\title{
Downscaling Advanced Microwave Scanning Radiometer (AMSR-E) Soil Moisture Retrievals Using a Multiple Time-Scale Exponential Rainfall Adjustment Technique
}

\author{
Chengmin Hsu ${ }^{1}$, Lynn E. Johnson ${ }^{2 *}$, Robert J. Zamora ${ }^{3}$, Timothy Schneider ${ }^{4}$ and Robert Cifelli ${ }^{3}$ \\ ${ }^{1}$ CIRES, University of Colorado Boulder/NOAA Earth System Research Laboratory, Physical Sciences Division, Boulder, Colorado, USA \\ ${ }^{2}$ CIRA, Colorado State University, Fort Collins, Colorado, USA \\ ${ }^{3}$ NOAA Earth System Research Laboratory, Physical Sciences Division, Boulder, Colorado, USA \\ ${ }^{4}$ NOAA Earth System Research Laboratory, Global Systems Division, Boulder, Colorado, USA
}

\begin{abstract}
Hydrologic response at all resolutions is controlled by physical processes. Accurately capturing the physical process at a high-resolution is essential for down scaling many satellite observations at coarse resolutions. In this paper, a four-dimensional process representative soil moisture downscaling model is developed to downscale the Advanced Microwave Scanning Radiometer-EOS (AMSR-E) $25 \mathrm{~km}$ resolution soil moisture product. The model is composed of the calculation of an antecedent precipitation accumulation (APA) index to capture soil moisture spatial and temporal variations at the $500 \mathrm{~m}$ resolution, and the application of a Geographic Information System (GIS) to simulate physical processes which can regulate soil moisture changes throughout the watersheds. APA index, as a representation of the provisional value of soil moisture, is calculated by adopting an exponential formulation to synthesize the effects of infiltration, soil evaporative efficiency, and vegetation resistance on soil water content following precipitation. Five days of AMSR-E soil moisture derivatives spanning the start of the monsoon and the duration of the storm are selected for downscaling. The results show that soil moisture spatial variation is primarily controlled by the distribution of precipitation and soil properties. Subsequently relative soil moisture, radiation, and vegetation become significant in controlling landsurface fluxes and thus influence soil moisture variation as time progresses. The downscaled soil moisture data (500 $\mathrm{m}$ resolution) are assessed using in-situ soil moisture measurements from the National Oceanic and Atmospheric Administration (NOAA) Hydrometeorology Testbed (HMT) and the U.S. Department of Agriculture (USDA) Southwest Watershed Research Center (SWRC) Walnut Gulch Experimental Watershed (WGEW) observing networks. The root mean square error (RMSE) between the disaggregated and in-situ soil moisture is $0.034 \mathrm{vol} / \mathrm{vol}$. with percent bias (PBIAS) $0.85 \%$. The overall $R^{2}$ value is 0.788 .
\end{abstract}

Keywords: Advanced microwave scanning radiometer; Soil moisture; Downscaling; exponential rainfall adjustment technique; Geographic information system

\section{Introduction}

Many studies have pointed out the importance of soil moisture in controlling the partitioning of rainfall into runoff and percolation as well as the separation of incident solar energy into sensible heat and latent heat across the land-atmosphere interface. It is also notable for its influence on the evolution of weather, the rate of evaporation from the surface, eco-geomorphologic processes of arid hillside ecosystems, and vegetation photosynthetic functions [1-5]. High-resolution soil moisture distribution is therefore of immense value for understanding the complex interactions between meteorological, biological, and hydrological regimes occurring in river basins and can be used as initial states to advance a variety of forecasting models. For example, it can be utilized for deciding the probability of a flash flood occurrence in the event of a storm. High accurate high resolution soil moisture data can even be used to improve weather forecasting accuracy through data assimilation systems. To enhance the comprehension of landatmosphere interactions, researchers have coupled land surface models (LSMs) and numerical weather prediction models [6] over the past few years. Yet a lack of accurate information about spatial and temporal variation of soil properties, vegetation characteristics, moisture states, and many atmospheric forcing fields at high resolutions often hinders executing objective diagnoses on the accuracy of these coupling efforts and even results in employing erroneous initial states for simulations. Though LSMs can generate high resolution soil moisture at various depths, the simulated soil moisture at relatively high spatial resolutions are often biased due to the uncertainties of their parameterization, numerical integration, and various physical processes represented $[7,8]$. To resolve these problems, many researches have turned to new strategies, such as the development of simplified soil-moisture models [9-11], the application of data assimilation techniques [12,13], and the involvement of remote sensing data [14]. The importance of these strategies is that they offset mathematical simplicity and an authentic representation of the nonlinearity of land, atmospheric, hydrologic, and ecologic dynamics at the watershed scale.

There have been several downscaling techniques developed based on the spirit of these new strategies. For example, Sahoo et al. [15] employed a three dimensional Ensemble Kalman Filter to assimilate AMSR-E soil moisture to the NOAH LSM in order to estimate $1 \mathrm{~km}$ surface soil moisture. Their sensitivity tests demonstrated that data assimilation not only improves soil moisture estimation at both the

*Corresponding author: Lynn E. Johnson, 325 Broadway, R/PSD2, Boulder, CO, 80305, USA, Tel: 303-497-5322; E-mail: Iynn.e.johnson@noaa.gov

Received November 04, 2014; Accepted December 02, 2014; Published December 05, 2014

Citation: Hsu C, Johnson LE, Zamora RJ, Schneider T, Cifelli R (2015) Downscaling Advanced Microwave Scanning Radiometer (AMSR-E) Soil Moisture Retrievals Using a Multiple Time-Scale Exponential Rainfall Adjustment Technique. J Geophys Remote Sensing 4: 139. doi: 10.4172/2169-0049.1000139

Copyright: (c) 2015 Hsu C, et al. This is an open-access article distributed under the terms of the Creative Commons Attribution License, which permits unrestricted use, distribution, and reproduction in any medium, provided the original author and source are credited. 
Citation: Hsu C, Johnson LE, Zamora RJ, Schneider T, Cifelli R (2015) Downscaling Advanced Microwave Scanning Radiometer (AMSR-E) Soil Moisture Retrievals Using a Multiple Time-Scale Exponential Rainfall Adjustment Technique. J Geophys Remote Sensing 4: 139. doi: 10.4172/2169-0049.1000139

Page 2 of 15

surface and at deeper layers, but that it also can be used as a tool to provide balanced initial states for hydrologic modeling without relying on long initiation times. Based on developed topographical index and soil depth information, Pellenq et al. [16] downscaled the averaged value of near-surface and deep soil water content in a sub-watershed to a higher resolution. This method successfully represents the lateral flow mechanism in the downscaling process for the wet days. Merlin et al. $[17,18]$, on the other hand, developed a sequential method based on the thermal sensors and the soil evaporative efficiency model to downscale the airborne Polarimetric L-band Multi-beam Radiometer (PLMR) and space-borne Soil Moisture and Ocean Salinity (SMOS) derived soil moisture to hundred-meter resolutions. Other strategies adopted include the involvement of radar or visible/infrared data $[19,20]$ or the application of statistical techniques [22] in downscaling operations. Through the execution of new strategies, the roles of the related hydrologic, land, and surface atmospheric parameters in soil moisture formation at different resolutions have been better perceived. However, there are still several issues with these improvements: 1) a vertical scale mismatch between passive microwave remotely sensed surface soil moisture (i.e. less than $1 \mathrm{~cm}$ depth without the presence of L-band radar and passive microwave antenna technology [23]) and in-situ soil moisture measurement (5 $\mathrm{cm}$ depth); 2) a parameter deficit in depicting the contrasting effects of vegetation that increase soil moisture retention time [24-27] while decreasing soil water content through transpiration; 3) complexity in characterizing all related vertical and lateral land surface processes occurring in the watersheds at high resolution; 4) lack of proper expressions in the downscaling schemes to represent the observed phenomenon such as soil moisture rises very quickly (e.g. in hours) following random precipitation events and decreases exponentially (e.g. in days) in between precipitation events [28].

With the aim of addressing the aforementioned issues by balancing simplicity and utilizing the abilities of remote sensing observations, we developed a technique to downscale coarse-resolution AMSR-E surface soil moisture data. This technique emphasizes the replication of the soil water retention process through an exponential rainfall adjustment system. The resolution of AMSR-E is as coarse as $25 \mathrm{~km}$, but improved features at its lower frequency channels $(6.9,10.7$, and $18.7 \mathrm{GHz})$ allow it to enable better inspection of the Earth's surface and retrieve several geophysical parameters [29]. The terrain signal collected by the AMSR-E radiometer shows several strengths: the signal can penetrate cloud, noise caused by land surface roughness and vegetation cover can be kept to minimum, and the signal better capture soil moisture variations through the soil dielectric constant [30]. Distinguished from the previous research in the various aspects, our study makes the following contributions: 1) a matched vertical scale between the in-situ observations and downscaled soil moisture is achieved by extrapolating AMSR-E soil moisture to the $5 \mathrm{~cm}$ depth;2) insertion of physicallybased parameters (versus data assimilation or statistical approaches) into the exponential formulation can imitate the exponential soil moisture dry down mechanism and trace various factors' behaviors in the dry-down process; 3 ) the contrasting effect of vegetation increasing the retention time of soil water while decreasing soil moisture through evaporation is first explored in this downscaling method; 4) this is a four-dimensional (including time span to the previous 11 days) model using a Geographic Information System (GIS) platform. With this method, the physical processes occurring across watersheds, such as infiltration, evapotranspiration, runoff, flow accumulation, and saturation, are represented.

\section{Study Site and Data Development}

\section{The study site}

The study site covers the Babocomari River watershed, Walnut Gulch Experimental Watershed, and their adjacencies extending to the southern boundary of the United States. The site is a portion of the San Pedro River basin in southeastern Arizona (Figure 1). The San Pedro River is a very important riparian area for hundreds of species of plants, mammals, reptiles, and insects. Soil moisture and groundwater effects on vegetation dynamics are apparent in this semi-arid environment. Stromberg et al. [31] pointed out that species distribution in this area is strongly related to depth to water table. Around $60 \%-80 \%$ of the annual precipitation on the study site occurs during the North American

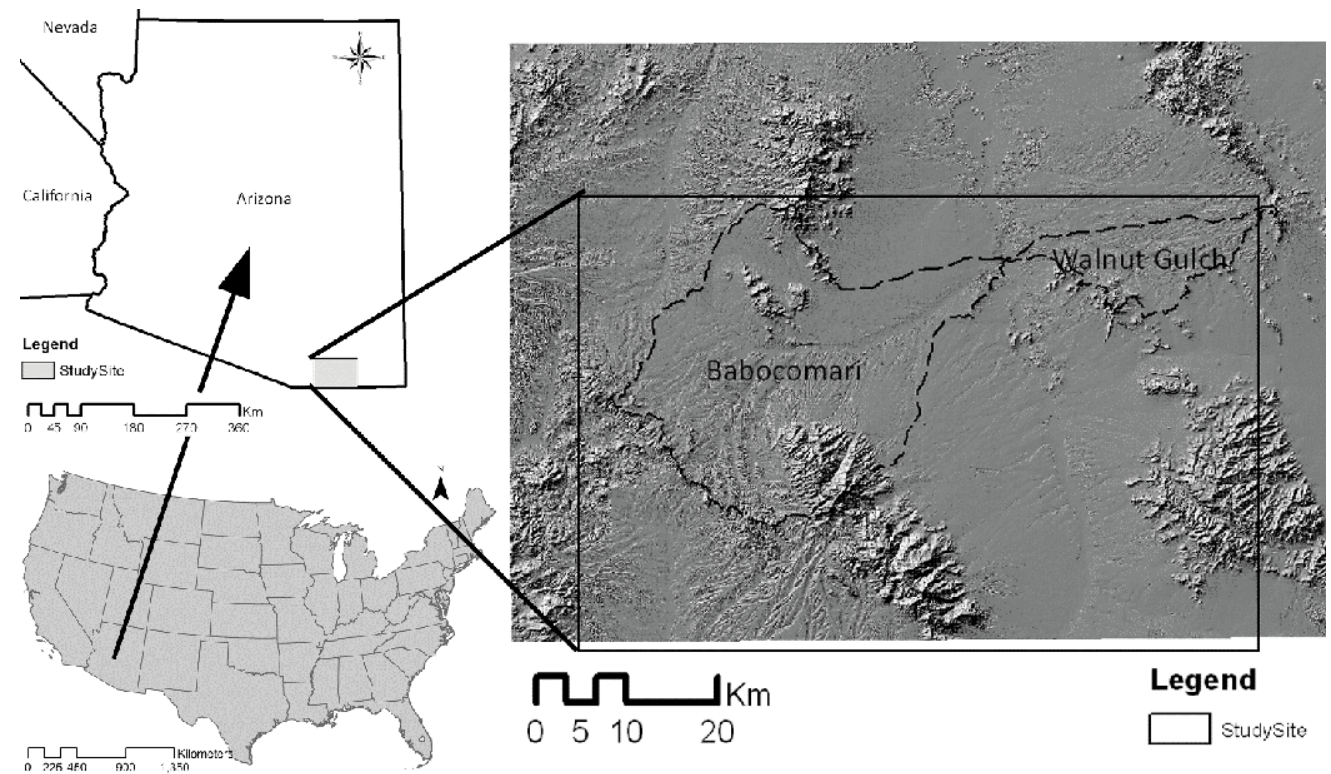

Figure 1: The study site is located in southeastern Arizona. The San Pedro River passes through the site with the Babocomari River watershed on the left and the Walnut Gulch River watershed on the right. 
Citation: Hsu C, Johnson LE, Zamora RJ, Schneider T, Cifelli R (2015) Downscaling Advanced Microwave Scanning Radiometer (AMSR-E) Soil Moisture Retrievals Using a Multiple Time-Scale Exponential Rainfall Adjustment Technique. J Geophys Remote Sensing 4: 139. doi: 10.4172/2169-0049.1000139

Page 3 of 15

monsoon as high intensity, convective thunderstorms of limited areal extent $[32,33]$. The moisture source for these thunderstorms is primarily the Gulf of California [34,35].

\section{AMSR-E soil moisture data}

AMSR-E soil moisture data provides global coverage with a nominal spatial resolution of $25 \mathrm{~km}$ and a temporal resolution of two days or less. Two sources of soil moisture data are used in the preliminary comparison to understand their quality: 1) NASA's data generated using the Njoku et al. [36]. Algorithm (referred as NASA-NSIDC product hereinafter) and 2) data developed by the Vrije Universiteit Amsterdam in collaboration with NASA (VUA-NASA) based on the Owe et al. algorithm [37]. The NASA-NSIDC soil moisture data used is retrieved based on the X-band $(10.65 \mathrm{GHz})$ brightness temperature. NASA-NSIDC soil moisture retrievals have been found to suffer extremely low temporal variability, especially during the growing season from May to October [21]. VUA-NASA provides two kinds of soil moisture products, which are retrieved from two different channels: the C-band (6.96 GHZ) and the X-band. As for the VUA-NASA data, given the widespread occurrence of radio frequency interference (RFI) in much of North America, Europe, and East Asia [38], we choose to use the data derived from the $\mathrm{X}$-band for this study.

The selected soil moisture stations and the corresponding $25 \mathrm{~km}$ pixels used for validating both sources of AMSR-E soil moisture are shown in Figure 2. The validation process was executed from July 1 , 2008 to August 20, 2008 by comparing the observation averages of the red spots $(5 \mathrm{~cm}$ depth) with the AMSR-E retrievals. When the study site is not covered by the AMSR-E navigation swath for a specific day, which occurred a few times in this study period, AMSR-E of the prior and subsequent days are averaged to represent soil moisture of that individual day. The gap-filling data was integrated into the 51 day time series for the purpose of comparing the two different AMSR-E products. Based on the data we collected in 2009, the VUA-NASA product shows a better agreement to the in-situ observations than the NASA-NSIDC product during the wet period (Figure 3). This verification result confirms the results of previous studies performed by Draper et al. and Wagner et al. [30,39]. Contrastingly, for the dry

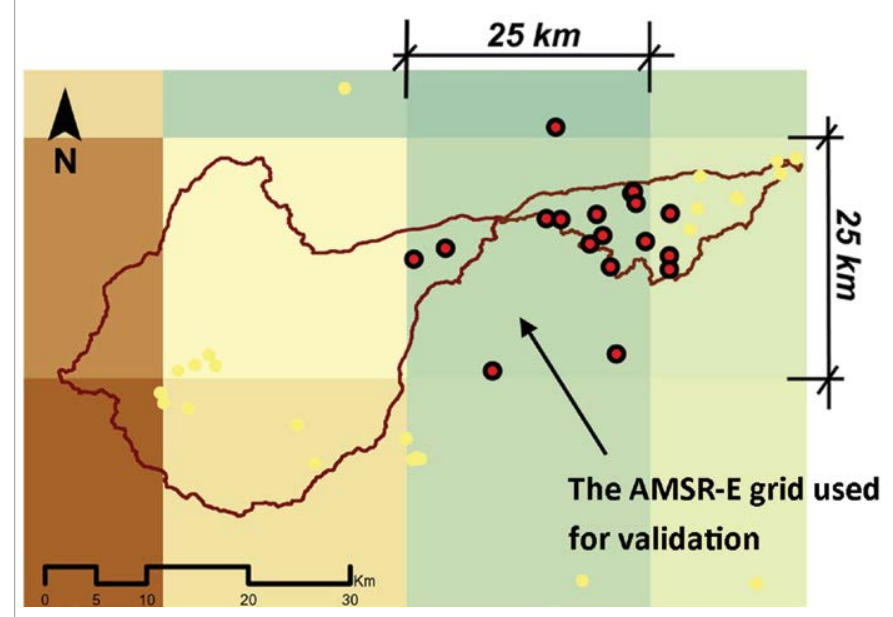

Figure 2: Nineteen soil moisture stations (red circles) out of the 31 stations (tabulated in Table 1) are selected for validating an AMSR-E soil moisture grid. The underlain grids represent the AMSR-E soil moisture data at a $25-\mathrm{km}$ resolution. Because the stations (red circles) within the grid are not evenly distributed, weights are assigned to the points to obtain the soil moisture average. period, soil moisture from the VUA-NASA product shows larger bias. However, after checking the rainfall distribution in the same period, we found that this bias was mainly caused by the variation of the soil water content observed at the different depths. From July 1 to July 19 , 2008, rain fell here and there but not intensively enough to wet the $5 \mathrm{~cm}$ depth layer. The easily wetted surface layer $(<1 \mathrm{~cm})$ thus shows more moisture than the deeper layer. Based on the verification result, we use the VUA-NASA data alone for downscaling. An evaluation of AMSR-E derived soil moisture over Australia indicates that the bias between the remotely sensed and ground-based soil moisture ranges from -0.01 to 0.19 vol./vol. [30].

\section{Precipitation and temperature}

The precipitation dataset was collected from the database of the precipitation gauge network established by the USDA Agricultural Research Service (ARS) SWRC and the NOAA HMT soil moisture observation networks. Data from 147 rain gauge stations were used in this study. The daily rain values from June 16, 2008 to August 20, 2008 were used for interpolation. The Inverse Distance Weight (IDW) algorithm was employed to interpolate the point data to raster format at a $500 \mathrm{~m}$ resolution. Figure 4 illustrates the interpolation results for July 21-24, 2008. The rain gauge stations in WGEW are installed with great density - the average distance between the stations is around $1.2 \mathrm{~km}$, while stations in the other areas are installed sparsely. Therefore, except for in WGEW, the uncertainty of the $500 \mathrm{~m}$ resolution interpolation becomes fairly noticeable at around $6 \mathrm{~mm}$ of RMSE in wet periods and around $13 \mathrm{~mm}$ of RMSE for pre-monsoon periods. Basically, the impact of this rainfall uncertainty on soil moisture downscaling can be neglected because soil moisture stations are co-located with rain gauge stations and IDW interpolation produces minimal error at the stations.

Similar to the precipitation raster data, the daily temperature raster data was derived using the IDW algorithm and data from 18 stations. But given diurnal temperature variation and its relationship to the daily cycle of surface evapotranspiration, we averaged the observed temperature in the 12 hour period (6:30 AM to 6:30 PM Local Time) as the daily average at each station. The PRISM (Parameterelevation Regressions on Independent Slopes Model) monthly average maximum temperature product is also involved in the interpolation process. First, the ratio of the temperature station daily average against the PRISM temperature monthly climatology is calculated. Second, this ratio is interpolated using the IDW algorithm. Third, the interpolated daily ratio is multiplied to the PRISM monthly average maximum temperature to get the temperature daily average grid. In this study, the daily air temperature grid is used to calculate air temperature effects on the vegetation canopy resistance factor and subsequently on evapotranspiration. The logic is that the higher the air temperature effect (ranging from 0 to 1 ), the higher the possibility of evapotranspiration loss and therefore the lower the soil water content.

\section{In-situ soil moisture data}

There are a total of 31 stations (Table 1) involved in validation. The soil moisture measured at a $5 \mathrm{~cm}$ depth represents the data used for validation. Geographic agreement between the $25 \mathrm{~km}$ grids of the Antecedent Precipitation Accumulation (APA) mean and the AMSR-E grids is critical for ensuring correct downscaling calculation. Therefore, the selection of the validation stations is based on the criteria that the stations need to be located in areas where AMSR-E grids and the domain of the Soil Survey Geographic (SSURGO) data base of the Cochise and Santa Cruz Counties overlap more than $90 \%$. The NOAA-HMT Arizona soil moisture observational stations are 
Citation: Hsu C, Johnson LE, Zamora RJ, Schneider T, Cifelli R (2015) Downscaling Advanced Microwave Scanning Radiometer (AMSR-E) Soil Moisture Retrievals Using a Multiple Time-Scale Exponential Rainfall Adjustment Technique. J Geophys Remote Sensing 4: 139. doi: $10.4172 / 2169-0049.1000139$

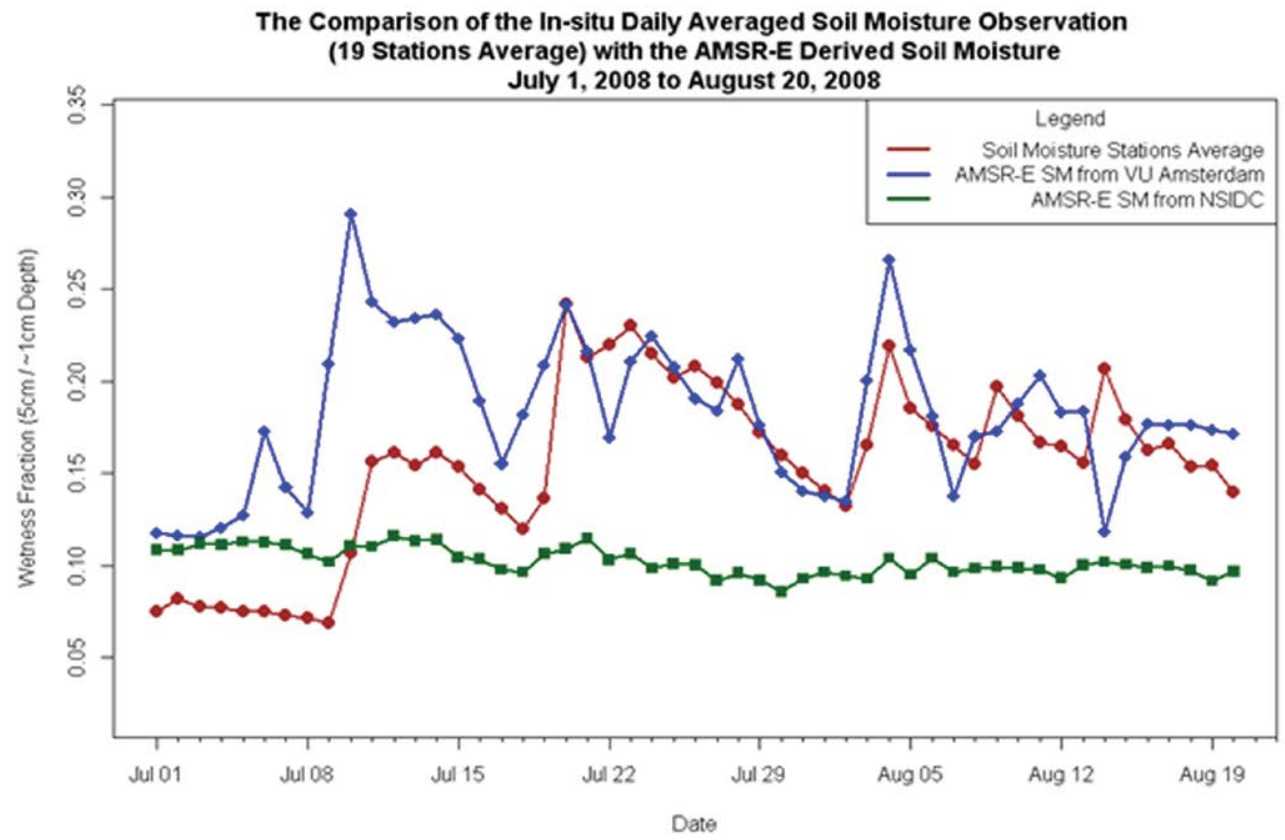

Figure 3: The plot of the soil moisture products of NASA-NSIDC, VUA-NASA, and the in-situ soil moisture observation illustrates the quality of the different products. The NASA-NSIDC's product shows poor quality in recoding the soil moisture fluctuation, whereas VUA-NASA's product has better quality. Notice that the 2008 Monsoon season started after July 10, 2008. That the in-situ soil moisture observations (5-cm depth) were consistently $\sim 5 \%$ drier than the VUA-NASA soil moisture product ( 1-cm depth) in the period from July 1 to July 19 indicates that soil moisture at the shallow layer (5-cm depth) is usually drier than surface soil moisture ( 1 $\mathrm{cm}$ depth) during the dry period.
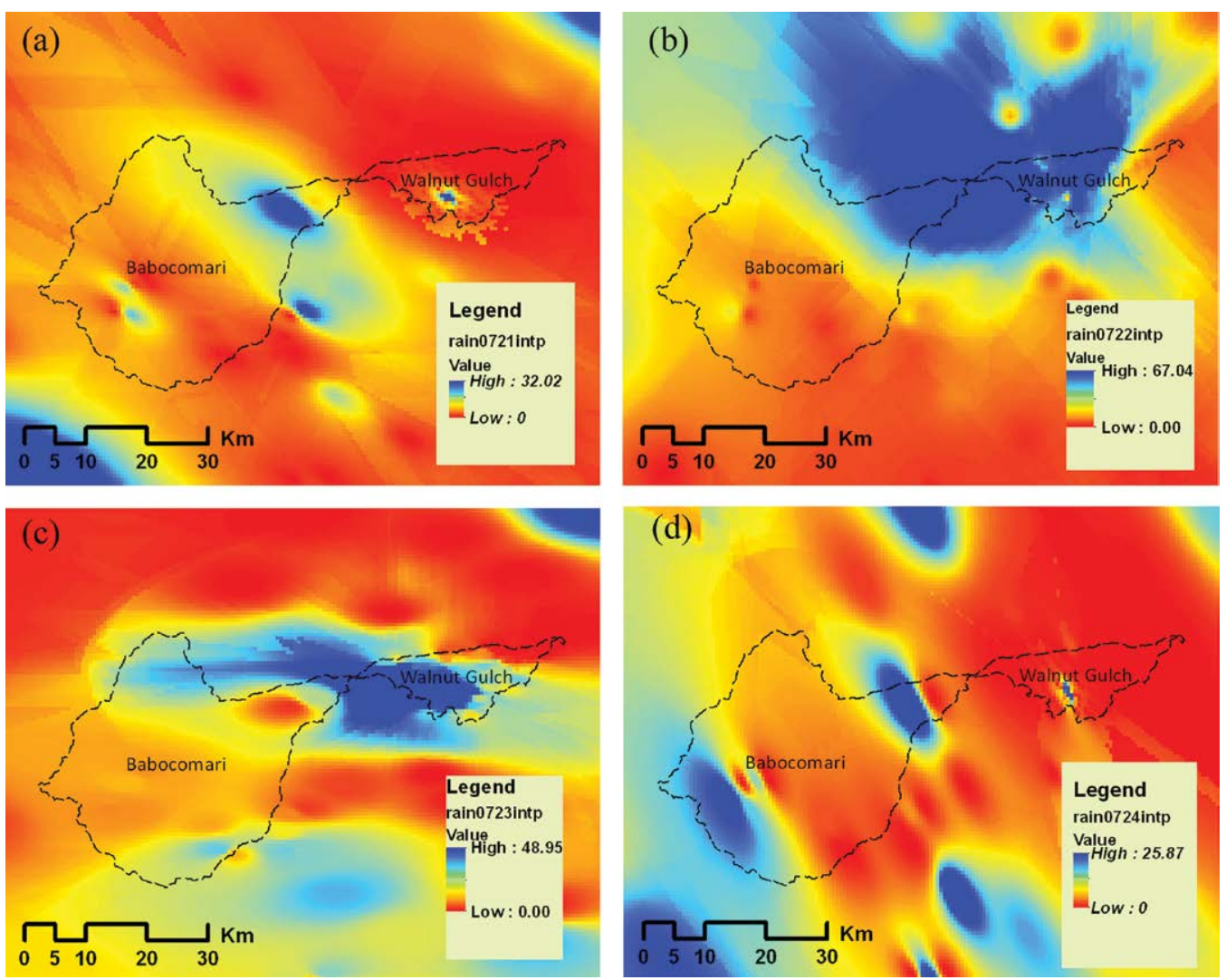

Figure 4: Rain interpolation at a 500-m resolution on (a) July 21, 2008, (b) July 22, 2008, (c) July 23, 2008, and (d) July 24, 2008 using an Inverse Distance Weight algorithm. The unit used is $\mathrm{mm}$. This plot shows that a storm event occurred on July 22 and 23, 2008. 
Citation: Hsu C, Johnson LE, Zamora RJ, Schneider T, Cifelli R (2015) Downscaling Advanced Microwave Scanning Radiometer (AMSR-E) Soil Moisture Retrievals Using a Multiple Time-Scale Exponential Rainfall Adjustment Technique. J Geophys Remote Sensing 4: 139. doi: 10.4172/2169-0049.1000139

Page 5 of 15

\begin{tabular}{|c|c|c|c|c|c|}
\hline Station & Agency & $\begin{array}{c}\text { East } \\
\text { (UTM 12N) }\end{array}$ & $\begin{array}{c}\text { North } \\
\text { (UTM 12N) }\end{array}$ & Land Cover & $\begin{array}{c}\text { Bulk Density @ } 5 \mathrm{~cm} \\
\text { Depth }\left(\mathrm{g} / \mathrm{cm}^{3}\right)\end{array}$ \\
\hline RG3_WGEW & USDA SWRC & 581203.5260 & 3509763.9530 & Shrub & 1.34 \\
\hline RG14_WGEW & USDA SWRC & 585442.0000 & 3507187.0000 & Shrub & 1.3 \\
\hline RG18_WGEW & USDA SWRC & 586710.0000 & 3508098.0000 & Shrub & 1.53 \\
\hline RG20_WGEW & USDA SWRC & 587481.7170 & 3504934.0150 & Shrub & 1.42 \\
\hline RG34_WGEW & USDA SWRC & 590946.0000 & 3507458.0000 & Shrub & 1.46 \\
\hline RG37_WGEW & USDA SWRC & 593303.0000 & 3506068.0000 & Shrub & 1.31 \\
\hline RG40_WGEW & USDA SWRC & 593360.0000 & 3510286.0000 & Shrub & 1.58 \\
\hline RG46_WGEW & USDA SWRC & 595287.7480 & 3508647.0740 & Grass & 1.4 \\
\hline RG57_WGEW & USDA SWRC & 596089.0000 & 3510781.0000 & Grass & 1.43 \\
\hline RG76_WGEW & USDA SWRC & 582624.0000 & 3509679.0000 & Shrub & 1.36 \\
\hline RG82_WGEW & USDA SWRC & 600154.0000 & 3511680.0000 & Grass & 1.31 \\
\hline RG100_WGEW & USDA SWRC & 593266.0000 & 3504720.0000 & Shrub & 1.46 \\
\hline RG401 & USDA SWRC & 568321.0000 & 3486006.0000 & developed & 1.38 \\
\hline RG402 & USDA SWRC & 568412.0000 & 3485884.0000 & Shrub & 1.38 \\
\hline RG403 & USDA SWRC & 568806.0000 & 3485822.0000 & Shrub & 1.38 \\
\hline RG404 & USDA SWRC & 568636.0000 & 3485822.0000 & Shrub & 1.38 \\
\hline RG405 & USDA SWRC & 571258.0000 & 3506843.0000 & Shrub & 1.33 \\
\hline RG415 & USDA SWRC & 556530.0000 & 3489184.0000 & evergreen forest & 1.43 \\
\hline RG420 & USDA SWRC & 567959.0000 & 3485736.0000 & Shrub & 1.38 \\
\hline RG422 & USDA SWRC & 544831.0000 & 3494627.0000 & Shrub & 1.35 \\
\hline RG423 & USDA SWRC & 547920.0000 & 3496185.0000 & Shrub & 1.35 \\
\hline RG424 & USDA SWRC & 558346.0000 & 3485444.0000 & evergreen forest & 1.37 \\
\hline RG426 & USDA SWRC & 567342.0000 & 3487870.0000 & Shrub & 1.43 \\
\hline Freeman.Spring & NOAA HMT & 543053.8167 & 3492371.0658 & Shrub & 1.58 \\
\hline Whetstone & NOAA HMT & 568097.7261 & 3505744.3389 & Shrub & 1.32 \\
\hline Black.Oak & NOAA HMT & 543395.3493 & 3491397.9963 & Shrub & 1.65 \\
\hline Kendall.SoilHydro. & USDA SWRC & 599893.9150 & 3511857.3400 & Shrub & 1.35 \\
\hline LuckyHill.TDR.L1 & USDA SWRC & 589567.4520 & 3512295.9430 & Shrub & 1.48 \\
\hline LuckyHill.TDR.L2 & USDA SWRC & 589792.9490 & 3512420.2640 & Shrub & 1.48 \\
\hline LuckyHill.SoilHydro. & USDA SWRC & 589799.1730 & 3512411.8050 & Shrub & 1.48 \\
\hline SCAN & USDA NRCS & 589995.1053 & 3511264.0385 & Shrub & 1.48 \\
\hline
\end{tabular}

Table 1: The validation stations, locations, land cover, and bulk density at a $5 \mathrm{~cm}$ depth.

located mainly in the headwaters of the Babocomari River with one station (Whetstone) located near the junction of the Babocomari River and the San Pedro River. Meanwhile, since 1990, the USDA SWRC has established a network of automated weather stations (AWSs), soil profile trenches and near-surface soil hydrology sites, co-located with rain gauges on the Walnut Gulch Experimental Watershed (WGEW) to measure soil moisture and soil temperature [40]. The soils of the study site are dominated by alluvial fan material, volcanic debris, and extensive layers of limestone conglomerate known as caliche [41]. At locations where caliche is present, soil moisture appears wetter.

\section{SSURGO data}

The attributes extracted from SSURGO for this research include surface texture, available water capacity, and bulk density, depth to any soil restrictive layer, percent clay, percent sand, water content, surface texture, saturated hydraulic conductivity, and hydro group. These properties are used to estimate the coefficients and the inputs for the downscaling model, such as $\mathrm{k}$ (soil water retention efficacy), Field Capacity (FC), relative infiltration rate, and characteristic evaporation resistance $\left(\mathrm{m} \mathrm{s}^{-1}\right)$. The soil water retention efficacy $(\mathrm{k})$, for instance, is determined based on the SSURGO attributes of "Percentage of Clay Average at a $5 \mathrm{~cm}$ Depth" $(\psi)$, "Surface Texture" $(\varphi)$, and "Depth to any Restrictive Layer" $(\delta)$. The coefficient estimation was first executed on SSURGO map unit polygons and then transformed to a raster format at a $50 \mathrm{~m}$ resolution. The $50 \mathrm{~m}$ resolution coefficient was then averaged to $500 \mathrm{~m}$ grids. SSURGO is generated based on the limited number of soil profiles and an understanding of the soil-landscape association by soil scientists. Still, there are several map units whose attributes need to be revised based on the knowledge obtained in the field campaign. Wherever a large discrepancy exists between in-situ measurements and the SSURGO data, the attributes of $\psi, \varphi$, and $\delta$ must be modified. For these locations, we used the bulk density data from the Soil Moisture Experiment 2004 (SMEX04) project [42] and in-situ sampling carried out by the NOAA-HMT staffs to infer more accurate attributes. For most of the map units, when there were no significant discrepancies between the in-situ observations and SSURGO found the three attributes of SSURGO were used directly to derive $\mathrm{k}$. The $\mathrm{k}$ coefficient was calculated with ranges from 0.2 to 1.15 by assuming a negative correlation to $\psi$ and a positive correlation to $\delta$. The attribute of $\varphi$ was employed in this k estimation process for executing minor adjustments. FC, on the other hand, is estimated based on the $1 / 3$ bar Water Content (WC) attribute and by cross-referencing to the numbers published in the book [43] and to the observations at the soil moisture stations.

\section{Moderate resolution imaging spectroradiometer (MODIS) data}

The MODIS data used in this study is MODIS/Terra MOD-13 250 $\mathrm{m}$ resolution 16 day Enhanced Vegetation Index (EVI). We choose 
Citation: Hsu C, Johnson LE, Zamora RJ, Schneider T, Cifelli R (2015) Downscaling Advanced Microwave Scanning Radiometer (AMSR-E) Soil Moisture Retrievals Using a Multiple Time-Scale Exponential Rainfall Adjustment Technique. J Geophys Remote Sensing 4: 139. doi: 10.4172/2169-0049.1000139

Page 6 of 15

to use EVI instead of the more widely used NDVI because of EVI's capability of eliminating background and atmospheric noises as well as its high quality of non-saturation. EVI uses the blue band to remove influences of residual atmosphere contamination caused by smoke and sub-pixel thin clouds on the red band. Thus, EVI is more responsive to canopy structural variations, including leaf area index (LAI), canopy architecture, canopy type, and plant physiognomy [44]. As for the surface energy and water flux concern, an accurate vegetation index will greatly reduce the uncertainty induced from ecological factors. The EVI data is then used to compute fractional vegetation cover and later used to model interactive effects with solar radiation on soil moisture variation. Our field observations confirm that the fractional vegetation cover data generated using EVI is more accurate than that generated by NDVI.

\section{NED}

The National Elevation Dataset (NED) was employed in this study to derive flow accumulation and solar radiation. A pixel (500 $\mathrm{m}$ resolution) with a larger flow accumulation means that there is a greater surface runoff from the pixels upstream flowing to that specific pixel and thus the soil of that pixel should be wetter, and vice versa. The natural logarithm of the flow accumulation value for each pixel is computed to represent the lateral flow processes occurring in the watersheds. The flow accumulation is calculated using the D8 algorithm in ArcGIS based on $100 \mathrm{~m}$ resolution NED and later aggregated to $500 \mathrm{~m}$ resolution. Based on investigation of satellite imagery and soil moisture stations records, high flow accumulation pixels (e.g. $\ln$ (Flow Accumulation) $>\sim 51$ ) always show much wetter surroundings. A threshold of the natural logarithm of flow accumulation (i.e. number of pixels) is therefore set at 52.55 to determine whether to add extra soil water content (\%) to the pixels. On the other hand, the solar radiation $\left(\mathrm{WH} / \mathrm{m}^{2}\right)$ estimation is to find the areas with much less or extraordinary incoming solar insolation. Normally the areas with much less solar insolation receive fewer hours of sunshine and therefore hold higher soil water contents. Figure 5 shows that low solar radiation received in the area surrounding the RG76 station is caused by mountain range blockage. Low solar radiation results in higher soil moisture states at the RG76 station. The total amount of radiation calculated for a specific area is the sum of direct and diffuse radiation of all sun map and sky map sectors, respectively. The equations for calculating direct insolation from the sun map sector and for computing the diffuse radiation for each sky sector can be seen in the method developed by Rich et al. [45] and enhanced by Fu and Rich [46].

\section{Methodology}

The methodology for retrieving high-resolution soil moisture is composed of two tasks: 1) developing a multiple time-scale exponential model to be used for calculating APA index and 2) creating a GIS model for downscaling AMSR-E soil moisture based on the APA index. After generating the downscaled soil moisture, validation and sensitivity analysis is executed. Validation and sensitivity testing explore the impact of the pattern of the land and atmospheric characteristics on soil moisture distribution through visualization, comparison, coefficient alternation, and statistical calculation. Five dates (Jul. 4, 5, 15, 24, and 25,2008$)$ were selected for testing the downscaling method. The selected days comprise all possible weather prototypes for southern Arizona: pre-monsoon, beginning of monsoon (but not on the days of major events), mid-storm, and post-storm.

\section{APA index calculation}

Based on a stochastic differential equation $[10,47,48]$, described the rate of change in soil moisture at the daily time scale as the sum of inputs and losses associated with the active soil layer. At the daily time scale, Instantaneous rainfall events can create an instantaneous jump in soil moisture through infiltration. Instantaneous jump in soil moisture state for a specific rainfall event is actually governed by the saturation deficit and the rainfall depth [11]. By overlooking surface-controlled runoff and assuming evapotranspiration and percolation are the only sources of losses between storms, they modeled soil moisture on a daily time-scale and expressed it as

$$
\langle s\rangle=\frac{1}{\eta \gamma}\left(\lambda-N e^{-\gamma}\right),
$$

where $s$ is the vertically-averaged daily relative soil water content of soil rooting depth;

$\eta$ is the normalized evapotranspiration loss under well water conditions, which can be expressed as $E T_{\max } / w_{0}$, where $w_{0}$ represents the maximum soil water capacity available to plants and can be expressed as the product of rooting depth times the difference of relative soil
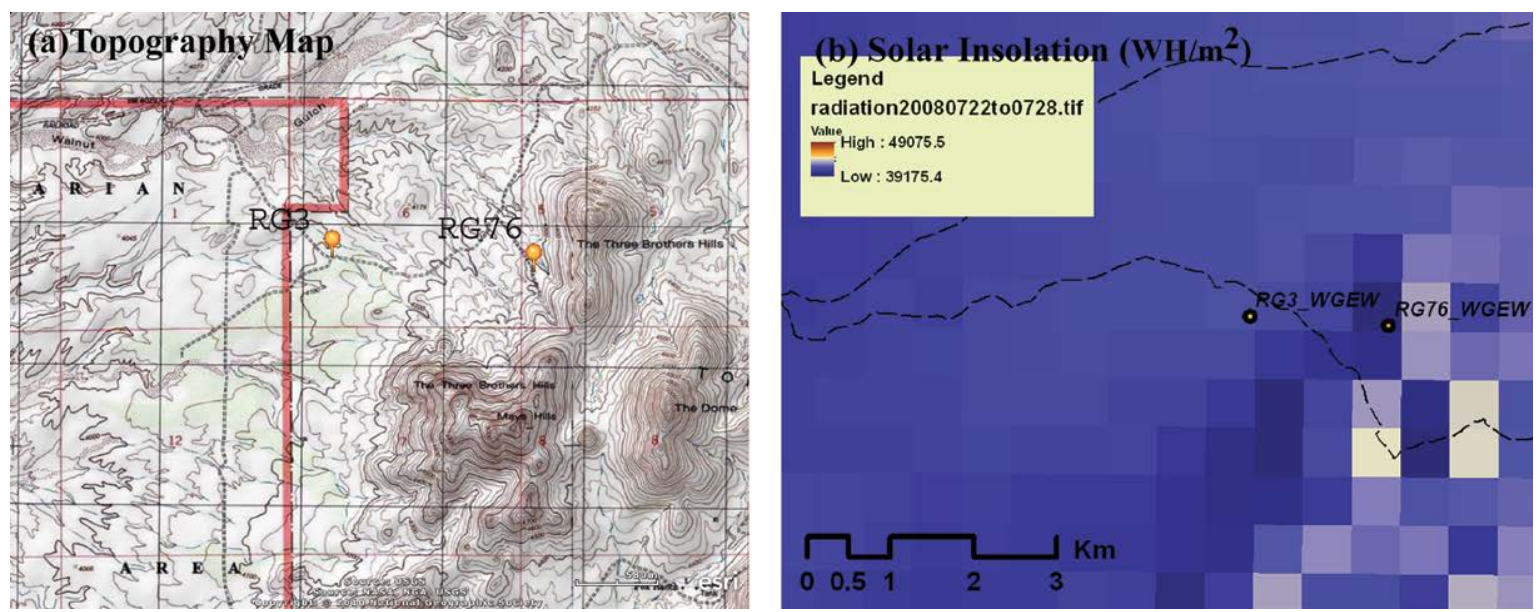

Figure 5: The comparison of the topography settings (a) and the generated solar radiation between Jul. 22, 2008 to Jul. 28,2008 (b) shows that less solar radiation, which is caused by mountain blocking, is received at the RG76 pixel (dark blue). The decreased radiation insolation makes the RG76 station appear much wetter than at the surrounding pixels. 
Citation: Hsu C, Johnson LE, Zamora RJ, Schneider T, Cifelli R (2015) Downscaling Advanced Microwave Scanning Radiometer (AMSR-E) Soil Moisture Retrievals Using a Multiple Time-Scale Exponential Rainfall Adjustment Technique. J Geophys Remote Sensing 4: 139. doi: 10.4172/2169-0049.1000139

Page 7 of 15

moisture between well watered conditions and the wilting point and $E T_{\max }$ represents potential evapotranspiration;

$\gamma=\mathrm{w}_{0} / \alpha$, where $\alpha$ is mean of the exponential rainfall distribution;

$\lambda$ denotes the rainfall frequency $\left(\right.$ day $\left.^{-1}\right)$;

and $\mathrm{N}$ is the Normalization constant for gamma function.

Equation (1) explains a soil moisture turnover process by first adjusting the impact of rainfall frequency on soil moisture variation with a normalized exponent of the relative available soil water capacity $\left(w_{0} / \alpha\right)$. Secondly, the adjusted rainfall field is then further attuned using potential evapotranspiration $\left(E T_{\max }\right)$. This conversion of the rainfall field to the soil moisture formulation is a stochastic operation requiring analyses of the rainfall field in multiple day ranges. It demonstrates the application of an exponential function and the partitioning of rainfall into infiltration and evapotranspiration at the daily time scale by parameterizing soil, vegetation, and climate.

Based on the philosophy of Equation (1), we develop an exponential model for calculating the APA index. The APA index represents the spatial distribution pattern of soil moisture at a $500 \mathrm{~m}$ resolution on a daily time-scale and becomes the basis for downscaling AMSR-E soil moisture. The APA index calculates the relative amount of the antecedent precipitation accumulation which can be retained in soil, by addressing effects of infiltration, evapotranspiration, temperature, vegetation cover, solar radiation, and soil moisture for 12 days. It can be expressed as

$$
\mathrm{APA}=P_{0} e^{f_{I} k f_{R_{0}} f_{T_{0}} f_{\theta_{0}}}+\sum_{i=-1}^{-11} P_{i} e^{i k f_{R_{i}} f_{T_{i}} f_{\theta_{i}}}
$$

The variables in Equation (2) are as follows: 1) $\dot{P}_{0}$ and $P_{i}$, respectively, represent rainfall on the target day of downscaling and rainfall on the preceding i day. 2) The $i$ variable represents the number of the preceding days to the target day of downscaling, ranging from -1 to -11 with " -1 " denoting one day before and "-11" eleven days before. 3) $f_{I}$ is the relative infiltration capability, derived from the SSURGO "Hydrologic Soil Group" attribute by assigning -0.08, -0.36, -0.64, and -0.92 for Group A, B, C, and D, respectively. 4) The $\mathrm{k}$ value ranges from 0.2 to 1.15 and is initially assumed to be negatively correlated to "Percentage of Clay Averaged at $5 \mathrm{~cm}$ Depth". It slightly adjusted later along with the "Depth to Any Restrictive Layer" and "Surface Texture" attributes. 5) $f_{R 0}$ and $f_{R i}$ denote integrated effects of solar radiation and vegetation on soil water retention for the target day and the preceding days, respectively. Considering that places with permanent shadow or that receive fewer hours of sunshine will have a higher soil-water content, we first scale the calculated solar radiation and assign a value of 1.07 to the $500 \mathrm{~m}$ resolution pixels whose scaled solar radiation is greater than 2.5 , a value of 0.48 to the pixels whose scaled solar radiation is less than -1.62 , and a value of 0.92 to 1 to the rest of the pixels, assuming they negatively correlate to the scaled solar radiation. This derived solar effect index is then multiplied by the vegetationinduced wet index, which ranges from 0.7 to 1 . The vegetation-induced wet index generated from EVI by assuming vegetation effect index is negatively correlated to EVI. 6) $\mathrm{f}_{\mathrm{TO}}$ and $\mathrm{f}_{\mathrm{Ti}}$, respectively, denotes the effect of air temperature on soil moisture formation for the particular day and for the preceding downscaling days. It is derived from a Jarvistype [49] stomatal resistance parameterization scheme. Based on the Jarvis-type scheme [51,52], the temperature effect factor is negatively associated to the total canopy resistance and positively influences evapotranspiration loss and thus has effects on soil moisture. The effect of the air temperature effect is formulated below:

$$
f_{T}=1-C_{t}\left(T_{r e f}-T_{a}\right)^{2},
$$

Where, $\mathrm{C}_{\mathrm{t}}=0.0016$;

$\mathrm{T}_{\text {ref }}=24.85^{\circ} \mathrm{C}$;

$\mathrm{T}_{\mathrm{a}}$, for air temperature.

Similar to the air temperature effect on evapotranspiration loss, $f_{\theta 0}$ and $f_{\theta i}$, respectively, represent the effect of soil moisture on evapotranspiration and thus on soil moisture variation for the targeted downscaling day and for its preceding days. The formulation used to model the soil evaporative efficiency is

$$
f_{\theta}=\left[0.5-0.5 \cos \left(\frac{\pi \theta}{\theta_{c}}\right)\right]^{0.35},
$$

where $\theta$ denotes absolute soil moisture state; and $\theta_{c}$ is the soil moisture at field capacity.

\section{Downscaling algorithm development}

The APA model described in the previous section addresses the possible retention of antecedent precipitation accumulation for soil of $5 \mathrm{~cm}$ depth. But, to attain strict correspondence (spatially and progressively) between AMSR-E soil moisture and APA output average $(25 \mathrm{~km})$, several adjustments are required. The adjustment mechanism incorporates steps such as allocating moisture runoff or leakage once super-saturation occurs, removing rainfall excess from super-saturation pixels, and extrapolating the near surface $(<1 \mathrm{~cm}$ depth ) AMSR-E product to APA calculating depth $(5 \mathrm{~cm})$. In fact, soil moisture in its approach to saturation can be characterized by a gradual asymptotic increase with surface runoff. Figure 6 illustrates the downscaling algorithm.

The downscaling process is composed of the following steps and encoded in a GIS platform:

1) APA index $(500 \mathrm{~m})$ is compared to the scaled FC layer $(500 \mathrm{~m})$ to decide if removal of saturation excess on certain pixels is necessary or not. For pixels whose APA index is greater than the scaled FC, the APA index at those pixels was immediately replaced by the scaled FC. The FC layer is obtained based on the numbers tabulated in Table 2 and SSUGO soil data.

2) The adjusted APA layer (500 $\mathrm{m}$ resolution) is aggregated (average) to a $25 \mathrm{~km}$ resolution and normalized.

3) The relative hydraulic conductivity $\left(\mathrm{K}_{\mathrm{r}}\right)$ is calculated from the averaged APA $(25 \mathrm{~km})$ using a Mualem-theory based equation developed by Brooks and Corey [53].

$$
K_{r}(s)=s^{(2+2.5 \lambda) / \lambda},
$$

Where s represents relative soil water content (effective saturation) and is defined by $S=\left(\theta-\theta_{\mathrm{r}}\right) /\left(\theta_{\mathrm{s}}-\theta_{\mathrm{r}}\right)$. $\theta_{\mathrm{s}}$ is the field capacity and $\theta_{\mathrm{r}}$ is the residual water content; $\lambda=-0.9615$.

4) AMSR-E soil moisture is re-sampled and aggregated to have its grid's $(25 \mathrm{~km})$ configuration and domain be exactly the same as that of the normalized APA $(25 \mathrm{~km})$. The re-sampled AMSR-E is then normalized.

5) Because the interaction between soil moisture near the surface 
Citation: Hsu C, Johnson LE, Zamora RJ, Schneider T, Cifelli R (2015) Downscaling Advanced Microwave Scanning Radiometer (AMSR-E) Soil Moisture Retrievals Using a Multiple Time-Scale Exponential Rainfall Adjustment Technique. J Geophys Remote Sensing 4: 139. doi: $10.4172 / 2169-0049.1000139$

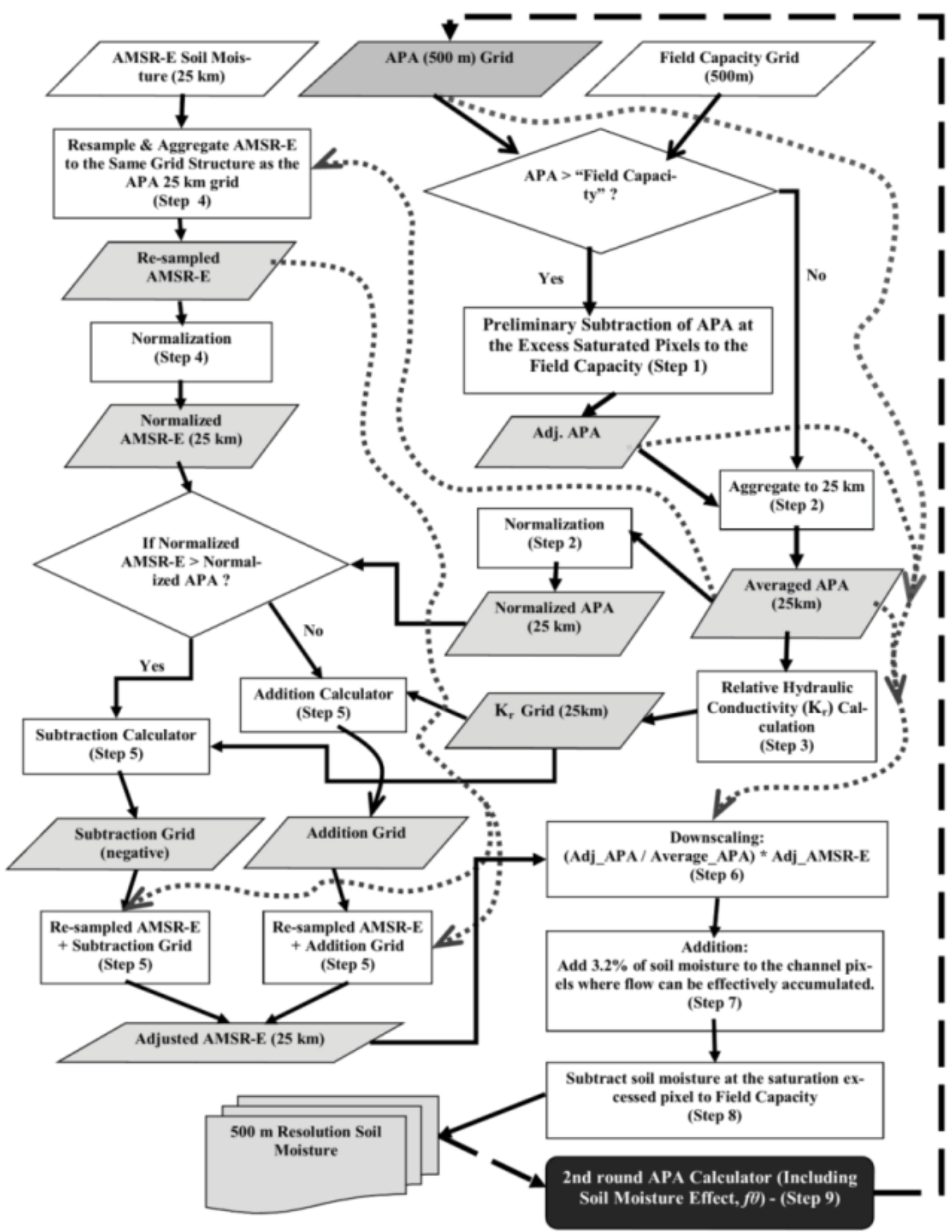

Figure 6: The AMSR-E soil moisture downscaling GIS model comprises normalization, saturation excess removal, adjustment (i.e. adjusting AMSR-E to a 5-cm depth soil moisture and adding soil moisture to the high flow accumulated pixels), and recursive downscaling.

and in the deeper layers is not clear [54], the normalized AMSR-E soil moisture is compared with the normalized APA index to determine how AMSR-E surface soil moisture can be extrapolated to $5 \mathrm{~cm}$ depth. If the normalized APA index is greater than the normalized AMSR-E index, the resampled AMSR-E soil moisture needs to be adjusted by adding a certain amount of soil moisture, and vice versa. We use unsaturated hydraulic conductivity $\left(\mathrm{K}_{\mathrm{r}}\right)$ derived from step 3) for calculating this adjustment amount. Since the gradient of the soil water content profile (analogous to $\gamma$ in Eq. (1)) should be very different in wet and dry periods and at each different AMSR-E grid, we assigned two sets of adjustment amounts for the two periods. For the subtraction case in the dry period, an adjustment amount ranging from -0.0036 to -0.148 with a positive correlation to the gradient of $\mathrm{K}_{\mathrm{r}}$ was assigned to each AMSR-E pixel. For the addition case in the dry period, the adjustment amount 
Citation: Hsu C, Johnson LE, Zamora RJ, Schneider T, Cifelli R (2015) Downscaling Advanced Microwave Scanning Radiometer (AMSR-E) Soil Moisture Retrievals Using a Multiple Time-Scale Exponential Rainfall Adjustment Technique. J Geophys Remote Sensing 4: 139. doi: 10.4172/2169-0049.1000139

Page 9 of 15

\begin{tabular}{|c|c|}
\hline Texture & Field Capacity $(\mathrm{V} \%)$ \\
\hline Sand & 10 \\
\hline Loamy sand & 12 \\
\hline Sandy loam & 18 \\
\hline Sandy clay loam & 27 \\
\hline Loam & 28 \\
\hline Sandy clay & 36 \\
\hline Silt loam & 32 \\
\hline Silt & 30 \\
\hline Clay loam & 36 \\
\hline Silty clay loam & 40 \\
\hline Silty clay & 45 \\
\hline Clay & 51 \\
\hline
\end{tabular}

Table 2: The field capacity of various soil types.

is small, ranging from 0.0007 and 0.01 with a negative correlation to $\mathrm{K}_{\mathrm{r}}$. For the subtraction case in the wet period, the adjustment should become smaller and the range from -0.0052 to -0.037 , which is assigned to each pixel based on assumption of a positive correlation to $\mathrm{K}_{r}$. For the addition case in the wet period, an adjustment amount ranging from 0.0052 to 0.044 with a negative correlation to $\mathrm{K}_{\mathrm{r}}$ was assigned to each AMSR-E pixel. These adjustment ranges were determined based on the detected soil moisture deviations between the AMSR-E soil moisture derivatives and the $5 \mathrm{~cm}$ depth observations as shown in Figure 3 as well as several preliminary adjustment experiments executed for the different AMSR-E grids covering the study sites. The subtraction and addition layer was then added to the respective subtraction or additionrequired grids of the resampled AMSR-E layer obtained from step 4).

6) The adjusted APA index $(500 \mathrm{~m})$ from step 1$)$ is divided by the average APA index (25 km) from step 2) and multiplied to the adjusted AMSR-E index from step 5) to obtain the preliminary downscaled soil moisture index $(500 \mathrm{~m})$.

7) $3.2 \%$ of soil moisture is added to pixels whose natural logarithm of flow accumulation is greater than 52.55. The purpose of this process is to account for the influence of surface/subsurface flow on downstream pixels.

8) The raster layer generated at step 7) is checked to see if there are still supersaturated pixels. A minor adjustment is executed on the pixels if their soil water content is found to be greater than the saturation level. This final adjustment thus produces the downscaled $500 \mathrm{~m}$ resolution soil moisture product.

9) To account for the soil moisture effect on the soil evaporative efficiency, a loop run was created. The downscaled soil moisture from step 8) was entered into the APA model for calculating $\mathrm{f}_{\theta}$ (Eq. (4)). The new generated APA index was then inserted into step 1) again to repeat the whole downscaling steps. This iterative mode of downscaling allows the soil moisture effect on soil evapotranspiration to be addressed.

\section{Validation and sensitivity analysis}

In this study, we use the coefficient of determination $\left(\mathrm{R}^{2}\right)$, root mean square error (RMSE), and percent bias (PBIAS) to evaluate the downscale results. The definition and the strength of these three model evaluation techniques are explicitly addressed in the paper by Moriasi et al. [55]. Three factors may impede the reliability of verification. First, the representativeness of in-situ soil moisture measurement at one point for describing soil moisture on a $500 \mathrm{~m}$ grid is not great. Soil exhibits great spatial variability even within relatively small areas, such as a $500 \mathrm{~m}$ square field [43]. Numerically equivalent soil moisture observations collected from two different stations can have

very different interpretations if soil moisture is interpreted based on differing soil properties at the two stations [56]. Second, accurate estimation of some soil attributes, such as field capacity, is very difficult when based on SSURGO data only. Third, in the process of transferring vector data (e.g. SSURGO map units) to raster $(500 \mathrm{~m}$ resolution), soil properties of very narrow zones are likely to disappear or be displaced onto an adjacent pixels that they do not belong to. All of these can cause the retrieved soil moisture data to deviate from ground-truth data. However, the NOAA-HMT and USDA SWRC soil moisture observational networks still furnish very reliable soil moisture information. To comprehend the relationship between the observations and the distribution pattern of the downscaled soil moisture grids surrounding the observation points, we carefully checked the locations of the stations by displaying the observational points against the SSURGO polygons. By doing this, the deviation between observed and downscaled soil moisture can be understood. A few stations were discarded as validation stations because uncertainty caused by the aforementioned complication was found or because the observation station was not well-calibrated. For example, based on SSURGO, the RG421 station is situated within a very narrow zone characterized by a high percentage of clay, but the converted $500 \mathrm{~m}$ grid does not sustain this soil attribute after transformation. RG421 is therefore abandoned as a validation station.

The sensitivity test is focused on the soil moisture effect, $f_{\theta}$, of Eq. (2). The exponent in Eq. (4) is tested alternatively with values of 2, 1, and 0.35 to find the optimal coefficient for calculating the soil moisture effect on evapotranspiration and for relating soil moisture effect onto the APA index formulation (Eq. (2)). The exponent value 1 and 2 for Eq. (4) constitutes the soil evaporative efficiency model developed by Noilhan and Planton [57] and by Lee and Pielke [58], respectively. Figure 7 plots the soil evaporative efficiency simulated using Eq. (4) with exponents of 2,1 , and 0.35 . Both forms of the model with exponents of 1 and 2 inflect around the middle of the soil moisture range [59] whereas the model with the exponent of 0.35 has a convex form. Some experiments have asserted that soil evaporative efficiency has more of a concave form at low soil moisture values $[58,60]$. In this paper however, $f_{\theta}$ represents the soil moisture effect at a $500 \mathrm{~m}$ resolution. It also conveys the impact of the diminishing infiltration rate as soil moisture increases. Therefore, the behavioral pattern of soil evaporative efficiency as a function of soil moisture is hypothesized to be somewhat different from previous research.

\section{Results and Discussion}

The multiple time-scale rainfall adjustment model illustrates positive downscaling performance, with an overall $\mathrm{R}^{2}$ value of 0.788 , a RMSE value of 0.034 vol./vol., and a PBIAS value of $0.85 \%$ (Figure 8 ). The performance measures of individual days are listed in Table 3. The $\mathrm{R}^{2}$ statistics indicate that the multiple time-scale exponential model functions very well for days before July 25, 2008. Both July 24 and 25, 2008 show an overestimation bias (PBIAS). In fact, RMSE gradually increases after the monsoon season started on July 10, 2008. These results are anticipated due to the fact that the soil was already fairly wet, thus, major storm events occurring after July 22, 2008 could quickly cause the soil to reach its field capacity. Thus, uncertainty in estimating the soil field capacity propagates into the downscaling model. On July 25, 2008, for instance, heavy rainfall passing through the central portion of WGEW (Figure 9) saturates soil in many places and thus erroneously estimation of field capacity degrades downscaling results for that day. On the other hand, for the dry period, due to considerable uncertainties occurring in the process of extrapolating AMSR-E 
Citation: Hsu C, Johnson LE, Zamora RJ, Schneider T, Cifelli R (2015) Downscaling Advanced Microwave Scanning Radiometer (AMSR-E) Soil Moisture Retrievals Using a Multiple Time-Scale Exponential Rainfall Adjustment Technique. J Geophys Remote Sensing 4: 139. doi: 10.4172/2169-0049.1000139

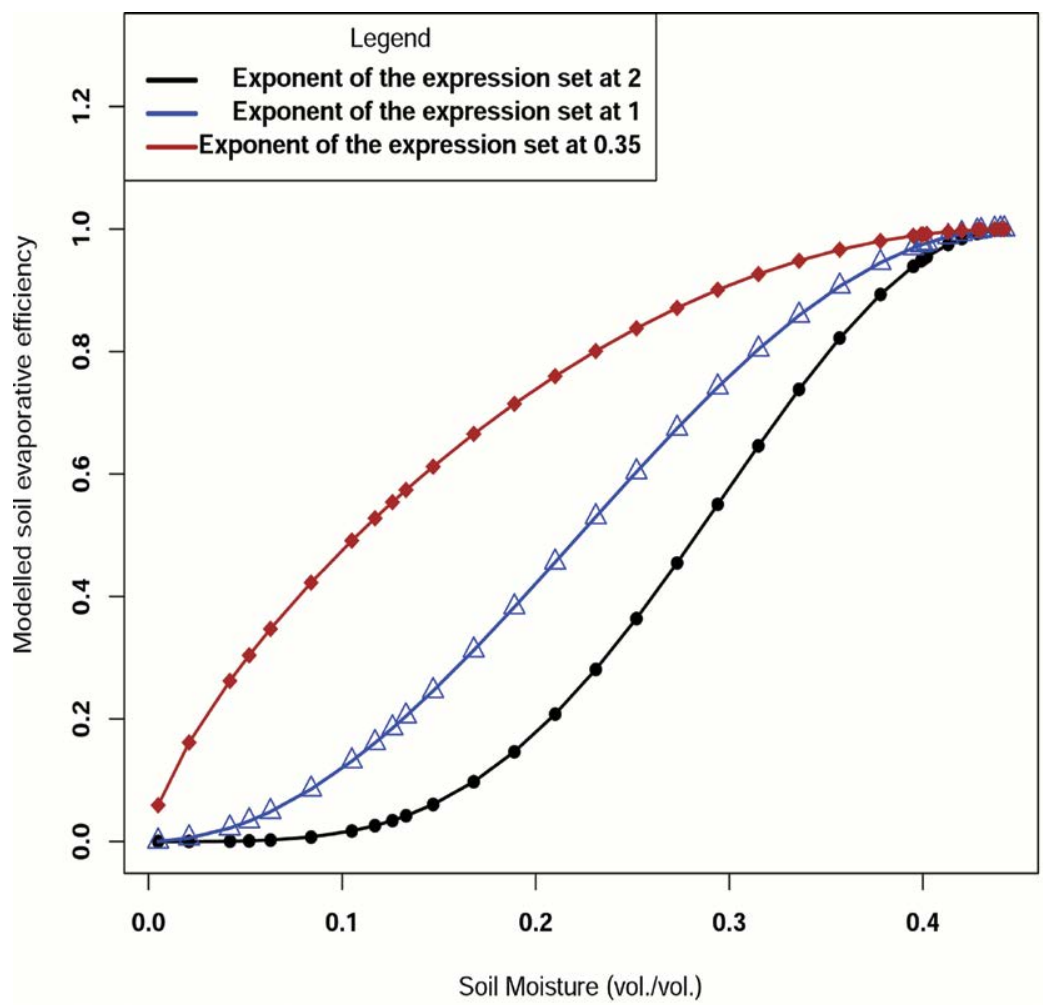

Figure 7: Simulations of soil evaporative efficiency using the expression, $\beta=\left(0.5-0.5 \cos \left(\pi \theta / \theta_{c}\right)\right)^{p}$, for a range of soil moisture values. In this paper, $p$ is set at 2,1 , and 0.35 respectively.

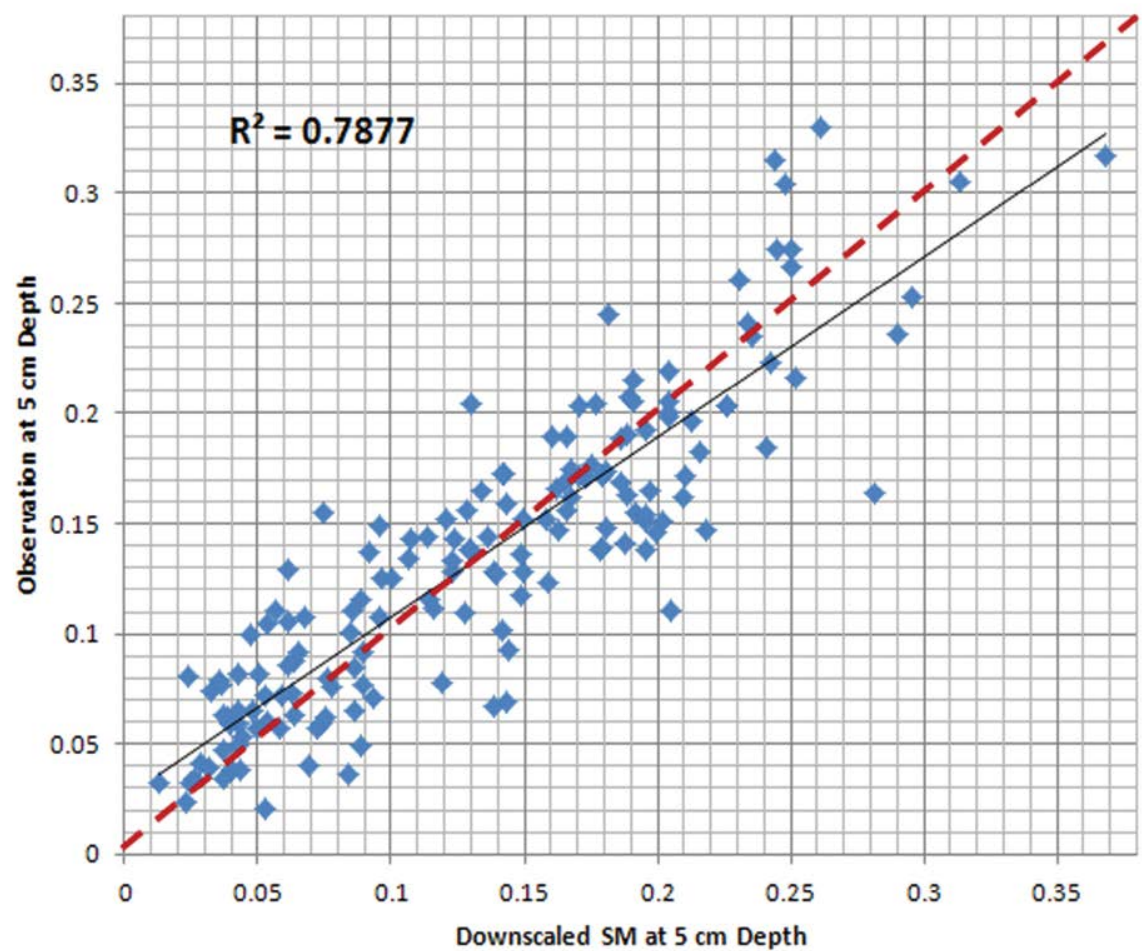

Figure 8: The relationship between soil moisture observation and downscaled soil moisture at a 500-m resolution for the selected 5 days of study is significant. One of the most noticeable outliers occurs at station RG46 for the July 25,2008 downscaling - the downscaled value is evidently under estimated. Based on the surface texture attribute of RG46 listed in Keefer et al. [40], the soil texture in the SSURGO database seems to be inaccurately recorded. This could cause the erroneous estimation of the k-exponent and the subsequently underestimation of soil moisture at a 500-m resolution in the downscaling operation. 
Citation: Hsu C, Johnson LE, Zamora RJ, Schneider T, Cifelli R (2015) Downscaling Advanced Microwave Scanning Radiometer (AMSR-E) Soil Moisture Retrievals Using a Multiple Time-Scale Exponential Rainfall Adjustment Technique. J Geophys Remote Sensing 4: 139. doi: 10.4172/2169-0049.1000139

Page 11 of 15

\begin{tabular}{|c|c|c|c|}
\hline $\begin{array}{c}\text { Date of } \\
\text { Downscaling }\end{array}$ & $\begin{array}{c}\text { R square (Based on 31 } \\
\text { points statistics) }\end{array}$ & RMSE & PBIAS (\%) \\
\hline $7 / 4 / 2008$ & 0.6267 & 0.026 & 7.38 \\
\hline $7 / 5 / 2008$ & 0.6169 & 0.026 & 1.56 \\
\hline $7 / 15 / 2008$ & 0.6711 & 0.045 & 1.34 \\
\hline $7 / 24 / 2008$ & 0.6287 & 0.033 & -0.72 \\
\hline $7 / 25 / 2008$ & 0.5299 & 0.036 & -1.57 \\
\hline
\end{tabular}

Table 3: Comparison of the validation statistics for the downscaling results on the individual date of simulation.

to a $5 \mathrm{~cm}$ depth, downscaling results often show a tendency toward underestimation bias for this period (e.g. downscaling on 7/4/2008).

The downscaled soil moisture layers at $500 \mathrm{~m}$ resolution for July 5 and July 24 are shown in Figure 10. July 5 and July 24 are prototypical examples of the dry and wet (after the major event) periods, respectively. When compared to the "Ksat" or "k exponent" distribution displayed in Figure 11, the downscaled soil moisture pattern in Fig. 10 exhibits correspondence to the distribution pattern of these two soil property indices. This correspondence indicates the governance of soil-physical properties, in addition to the power of precipitation distribution, in controlling soil moisture distribution patterns. In this research, the involvement of the soil property related exponent (i.e. $\mathrm{k}$ ) in the APA index calculation has been proven effective in the downscaling operation. Also, in Figure 10, there are some perceptible "break-lines" in the downscaled soil moisture grids following the $25 \mathrm{~km}$ grid edges of the original AMSR-E images. The soil moisture value distinctions at each of the $25 \mathrm{~km}$ grids make these "break-lines" inevitable because the calculation of the $500 \mathrm{~m}$ resolution APA variability is executed within each of the $25 \mathrm{~km}$ grids. Figure 9 displays a homogeneously wet area in the northern central part of WGEW on July 25, 2008, further confirming the influential effect of soil properties on soil moisture distribution. Based on the SSURGO data set, the northern central area of WGEW has a medium rate of infiltration, but the soil became saturated quickly during the event because the precipitation rate exceeded the infiltration rate, causing the appearance of a consistently wet area. Atchley and Maxwell [27] pointed out that the land surface becomes more uniformly wet as long as the rate of precipitation is greater than the rate of infiltration.

The sensitivity test of the soil evaporative efficiency behaving pattern as a function of soil moisture, concave or convex, results in the finding that the application of 0.35 as the exponent of Eq. (4) generates the best downscaling accuracy (Table 4 ). In other words, the relationship between soil moisture and soil evaporative efficiency has more of a convex shape (Figure 7). The convex relationship indicates that soil water loss rate increases quickly as soil begins to saturate in the early wetting stages but gradually slows its rate of increase in the later wetting stages. In the formulation of Eq. (2), the variables $f_{I}$ and $\mathrm{f}_{\theta}$ act like interactive exponents and should be considered together. When soil moisture approaches its field capacity, evaporation efficiency approaches a maximum and infiltration rate simultaneously decreases to its minimum rate. Conversely, when soil moisture is at a low level, infiltration rate is high and the soil becomes wet quickly. Thus, soil evaporation loss increases quickly. This combined effect of infiltration and soil moisture on soil water loss pattern explains why the relationship between soil evaporative efficiency and soil moisture has a
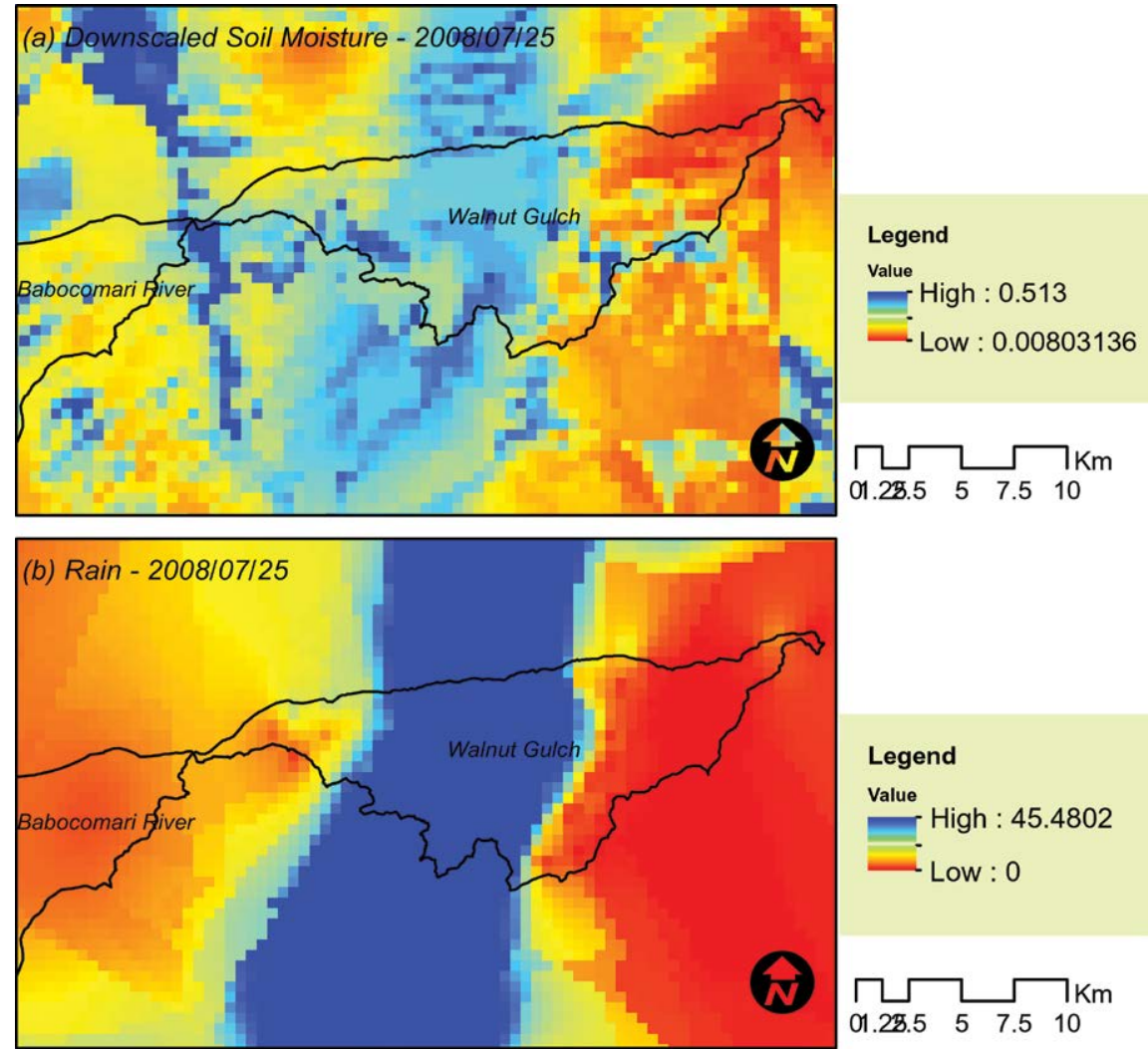

Figure 9: The northern central part of the Walnut Gulch Experimental Watershed - plot (a) is "evenly wet," compared with the other portions of the model domain. Plot (b) shows heavy rain on July 25, 2008, passing through the central portion of the WGEW. The homogeneously wet area at the northern-central part of the WGEW imples that the infiltration rate for this area has become relatively small, as the infiltrated precipitation has accumulated since the monsoon season started. 
Citation: Hsu C, Johnson LE, Zamora RJ, Schneider T, Cifelli R (2015) Downscaling Advanced Microwave Scanning Radiometer (AMSR-E) Soil Moisture Retrievals Using a Multiple Time-Scale Exponential Rainfall Adjustment Technique. J Geophys Remote Sensing 4: 139. doi: 10.4172/2169-0049.1000139
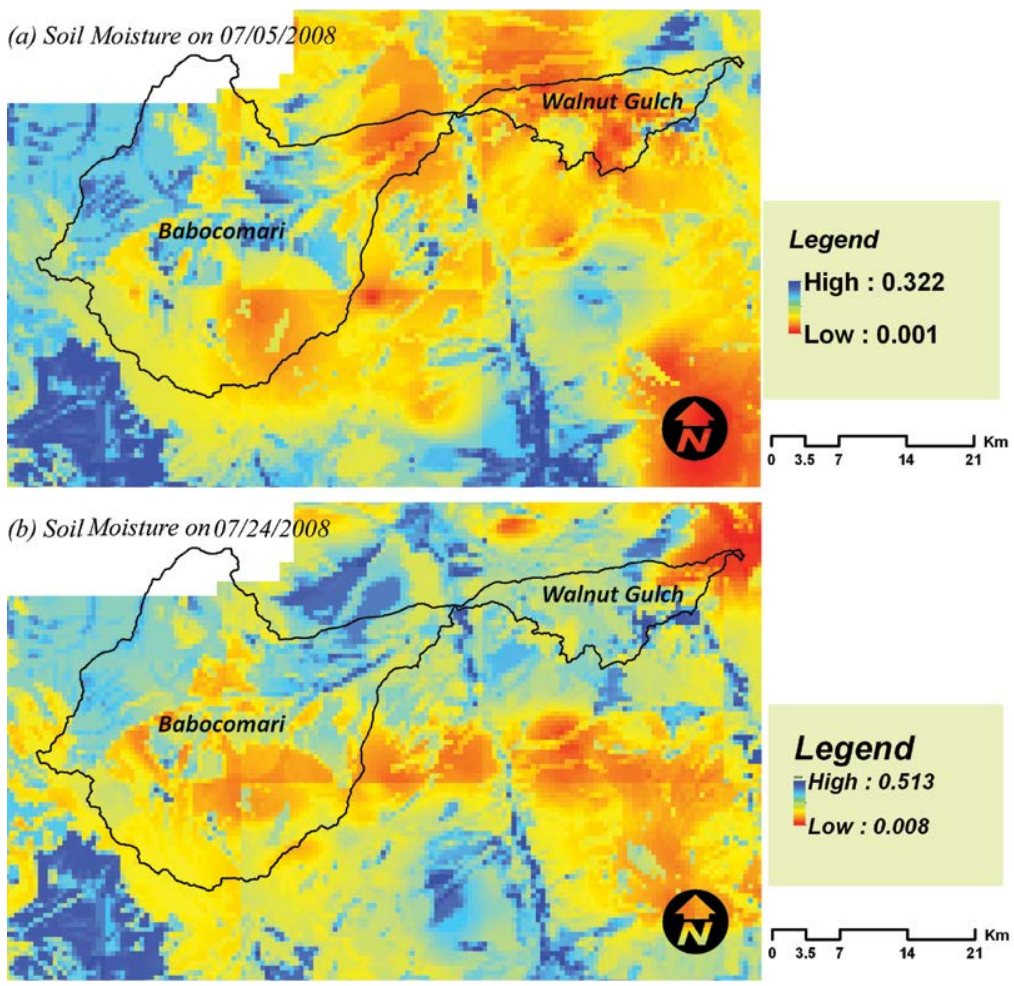

Figure 10: Plots (a) and (b) show examples of the downscaled soil moisture for July 5, 2008 and July 24, 2008, respectively, at a 500-m resolution. Notice that the value range of the legend is very distinctive for the two different days. Without further smoothing the grids, the $25-\mathrm{km}$ grid blocks for the original AMSR-E images are still perceptible. The July 5, 2008 date occurs before the monsoon and the July 24, 2008 date occurs after the monsoon. Regardless of precipitation inducing soil moisture fluctuation, the soil moisture distribution pattern on the both days is quite similar to each other. This phenomenon underscores the dominance of the soilphysical properties on soil moisture evolution.
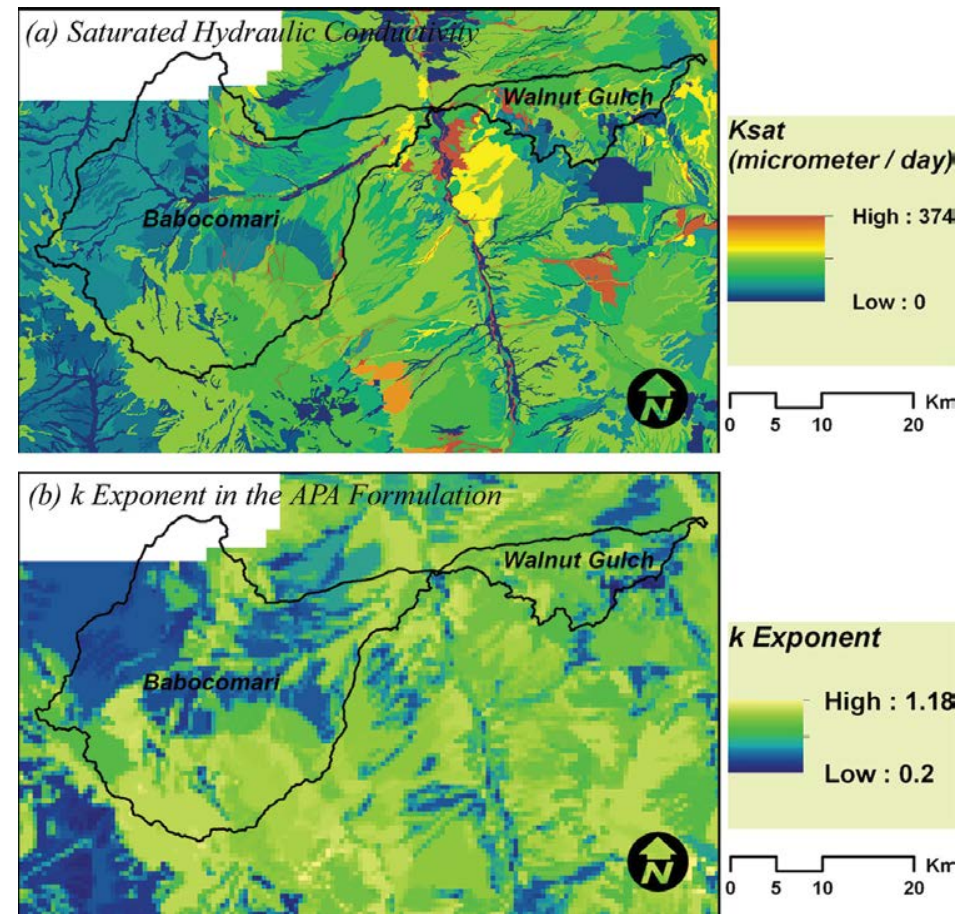

Figure 11: The saturated hydraulic conductivity $\left(\mathrm{K}_{\text {sat }}\right)$ distribution pattern (Panel a) is similar to the spatial distribution pattern of the downscaled soil moisture (e.g. Figure 10). $\mathrm{K}_{\text {sat }}$ is used to calculate $\mathrm{K}_{r}$ in Step 3 in the AMSR-E soil moisture downscaling GIS model (Figure 6). Furthermore, Panel (b) illustrates that the same distribution similarity can be found from the attribute "Percentage of Clay Averaged at a 5-cm Depth", which is used to generate the k exponent in Eq. (2). 
Citation: Hsu C, Johnson LE, Zamora RJ, Schneider T, Cifelli R (2015) Downscaling Advanced Microwave Scanning Radiometer (AMSR-E) Soil Moisture Retrievals Using a Multiple Time-Scale Exponential Rainfall Adjustment Technique. J Geophys Remote Sensing 4: 139. doi: 10.4172/2169-0049.1000139

Page 13 of 15

\begin{tabular}{|c|c|c|c|}
\hline $\begin{array}{c}\text { Exponent (p) of the Soil } \\
\text { Evaporative Equation (Eq. 8) }\end{array}$ & $\mathbf{R}^{2}$ & $\begin{array}{c}\text { RMSE (vol.I } \\
\text { vol.) }\end{array}$ & PBIAS (\%) \\
\hline 0.35 & 0.7877 & 0.034 & 0.85 \\
\hline 1 & 0.7384 & 0.038 & -1.46 \\
\hline 2 & 0.7108 & 0.040 & -2.27 \\
\hline
\end{tabular}

Table 4: The change of the soil moisture downscaling accuracy with the alteration of the exponent ( $p$ ) for the Eq. (4), $f_{\theta}=\left[0.5-0.5 \cos \left(\frac{\pi \theta}{\theta_{c}}\right)\right]^{p}$.

convex shape in this study. The convex shape relationship implies that Nature's "configuration" always promotes a certain kind of water cycle path to ease water transferring across phases and interfaces.

\section{Conclusions}

This study presents the application of a GIS-based multiple timescale exponential rainfall adjustment model to downscale the AMSR-E $10.65 \mathrm{GHz}$ brightness temperature soil moisture retrievals from 25 $\mathrm{km}$ to $500 \mathrm{~m}$. The created model represents an applicable method for retrieving $500 \mathrm{~m}$ resolution soil moisture at watershed scales. The methodology of retrieving high-resolution soil moisture is composed of two processes: 1) calculation of the APA index at each of the 500 $\mathrm{m}$ pixels using an exponential model framework and 2) downscaling of AMSR-E soil moisture based on the calculated APA index. The breakthrough of our work is the imitation of major processes occurring in the watershed scale using a GIS model. The developed GIS model can execute functions such as automatically deciding if soil moisture at a $5 \mathrm{~cm}$ depth of the $25 \mathrm{~km}$ resolution is drier or wetter than AMSR-E surface soil moisture, and extrapolating it to the $5 \mathrm{~cm}$ depth accordingly, removing saturation excesses, and adding flow accumulation-incurred spare water to downstream channel pixels if a storm occurs. The APA index is calculated for 12 days consecutively, allowing the effects of precipitation frequency and intensity (i.e. Eq. (1)) to be analyzed in the downscaling algorithm.

This paper unveils a physical process-based downscaling system highlighting several capabilities that are difficult for remote sensingbased systems. For example:

1) Soil moisture at the RG424 station consistently remains at a relatively high level. Theoretically, the setting of this station, such as a low "percentage of clay" (high conductivity), medium field capacity, and high evapotranspiration loss due to the soil moisture effect (Figure 7) as well as the temperature effect (i.e. temperature fairly close to $\sim 25^{\circ} \mathrm{C}$ in the summer periods), promotes drier soil. However, in mountainous areas, there are many exceptions contrary to the assumed dry soil situation. At the RG424 station exclusively, the opposite occurs because there are longer hours of shade casting caused by mountain morphology. The water stagnation effect occurring in the thick litter layer in vegetated areas also enhances higher soil water content (Figure 12). Moreover, a weakened wind effect caused by increased surface roughness in forest areas induces mild to high soil moisture states. The high soil moisture profile at RG424 is effectively simulated by our study.

2) Of all the parameters used in the downscaling process, the soil properties (from which we select "Percentage of Clay", "Surface Texture", and "Depth to Any Restrictive Layer" to calculate the $k$-value for use in the APA index calculation) are the most dominant factors influencing surface soil moisture distribution pattern given the same precipitation intensity. For example, low "Percentage of Clay" areas quickly dry since water infiltrates to deeper layers, and vice versa. But areas with caliche or other restrictive materials laid at shallow layers will retain water longer and appear wetter, even if their "Percentage of Clay" attributes are low. Generally, with the exception of those
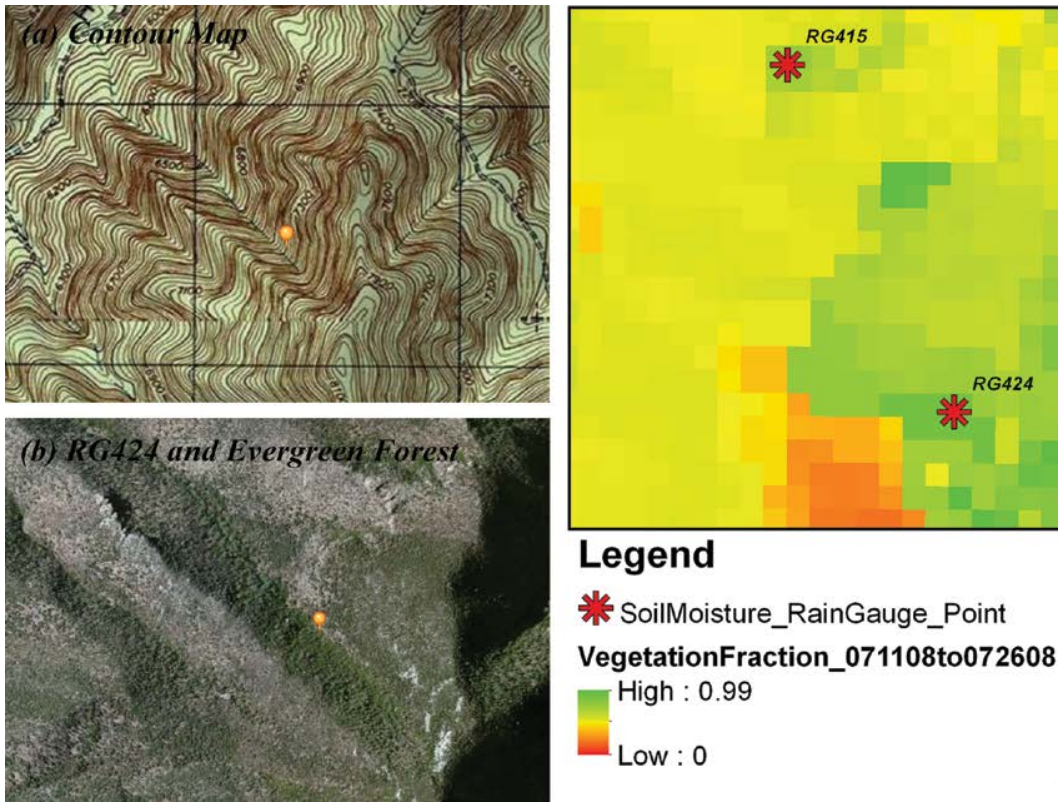

(c) Vegetation Fraction

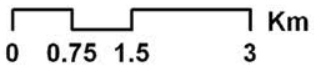

Figure 12: The consistently high soil moisture level at the RG424 station is effectively simulated by the GIS-based multiple-time scale exponential model. The RG424 is located in a trench in the mountains, receiving far less solar radiation due to shadows casted by mountain morphology (plot (a)). The station is also located in an area covered by an evergreen forest (plot (b)), so the infiltration rate for this area is high. When there is a storm, water flows from upstream areas and much of the water infiltrates the soil. Water loss due to evapotranspiration then becomes high. However, because of decreased radiation in this area, evapotranspiration loss is still confined and soil water content remains at a relatively high level. Plot (c) is the vegetation fraction calculated based on EVI data and has been integrated into the $\mathrm{f}_{\mathrm{R}}$ calculation. 
Citation: Hsu C, Johnson LE, Zamora RJ, Schneider T, Cifelli R (2015) Downscaling Advanced Microwave Scanning Radiometer (AMSR-E) Soil Moisture Retrievals Using a Multiple Time-Scale Exponential Rainfall Adjustment Technique. J Geophys Remote Sensing 4: 139. doi: 10.4172/2169-0049.1000139

Page 14 of 15

areas with extraordinary soil profiles (e.g. caliche) or solar radiation insolation (e.g. permanent shadow), the link between soil properties and soil moisture pattern is strong.

3) The integrated effect of vegetation and solar radiation, $f_{R}$, is another important factor in controlling soil moisture distribution and evolution in time. Basically, areas with higher EVI or longer hours of shadow caused by terrain constitution feature wetter soil moisture. It also implies these areas have higher infiltration rates. The vegetation effect can either reduce or increase soil water content. During the drying period, vegetation can often help to retain more water in the soil instead of releasing water flux into the atmosphere through transpiration because of shade on the ground and stomatal resistance effects. On the other hand, during the wet period, high soil moisture content will promote evapotranspiration, thus drying down soil water content.

4) The downscaling model is designed as an iterative system, which allows soil moisture effects $\left(f_{\theta}\right)$ to be realistically simulated.

5) The technique exploited to extrapolate the AMSR-E surface soil moisture to a $5 \mathrm{~cm}$ depth based on relative hydraulic conductivity and normalization of AMSR-E and APA index has proved to be appropriate. The effectiveness of this extrapolation method implies that soil moisture profile is related to relative hydraulic conductivity $\left(\mathrm{K}_{\mathrm{r}}\right)$ and to the wet/dry situation of soil.

\section{Future Efforts}

More work is needed in four areas to continue advancing this model. First, the downscaling model needs to be extended to a longer period to understand the seasonal and annual dynamics of the model parameters and to quantify model uncertainty. Second, to integrate more scientific detecting abilities into the exponential adjustment model, especially for downscaling work for large domains, MODIS MOD 16 products should be considered to replace a portion of the current exponents (i.e. $f_{R}, f_{T}, f_{\theta}$ ). The MOD 16 evapotranspiration products are generated based on the Penman-Monteith equation and thoroughly encompass the related parameters that may influence soil moisture fluctuation. Third, the system of simulating precipitation occurrence, ponding, excess saturation removal, and soil moisture addition at pixels downstream should be further explored using a kinetic wave model. Finally, future efforts should consider the effect of dynamic vegetation cover on soil moisture variation. In this paper, we investigate the vegetation effect with an emphasis on spatial variation of plants. In the future, soil moisture variation, as evapotranspiration rates and soil infiltration change throughout the seasons and during different storm intensities [61], should be explored. Scientific questions regarding vegetation effects are:

1) What proportion of the effects is for infiltration enhanced by vegetation canopy [62] against the incurred evapotranspiration loss? [63]?

2) How do climatic and seasonal regimes affect evapotranspiration

In this study, we develop an exponential downscaling framework emphasizing parameterizations of the governing processes in influencing soil moisture distribution at high resolutions. Future efforts in inter-season simulations and the involvement of more modern geospatial technology and remotely sensed data will expand the model's application to a variety of eco-regions.

\section{Acknowledgements}

Portions of the work presented in this paper were adapted from a chapter in the first author's doctoral dissertation, which would not have been completed without the financial support from NOAA HMT and the tuition support from the GIS program, Department of Civil Engineering, University of Colorado Denver The authors also thank Robert Parinussa from the Vrije Universiteit Amsterdam, Netherland for providing access to various AMSR-E related products. Specia thanks go to the staff members of NASA National Snow and Ice Data Centre for explaining the data format and way to process it. We also greatly appreciate the constructive suggestions of the two anonymous reviewers. The authors found the comments of Dr. Jian-Wen Bao and Dr. Sergey Matrosov to be very helpful.

\section{References}

1. Houser PR, Shuttleworth WJ, Famiglietti JS, Gupta HV, Syed KH, et al. (1998) Integration of soil moisture remote sensing and hydrologic modeling using data assimilation. Water Resour. Res. 34: 3405-3420.

2. Sarah $P$ (2002) Spatial patterns of soil moisture as affected by shrubs, in different climate conditions. Environ. Monitoring Ass 73: 237-251.

3. Katra I, Blumberg DG, Lavee h, Sarah P (2007) Spatial distribution dynamics of topsoil moisture in shrub microenvironment after rain events in arid and semiarid areas by means of high-resolution maps. Geomorphology 86: 455-464.

4. Mostovoy GV, Anantharaj VG (2008) Observed and simulated soil moisture variability over the lower Mississippi Delta Region. Amer. Meteor. Soc 9: 11251150 .

5. Entekhabi D, Reichle RH, Koster RD, Crow WT (2010) Performance metrics for soil moisture retrieval and application requirements. J. Hydrometeor 11: 832840.

6. Santanello Jr, Joseph A, Peters-Lidard CD, Kumar SV (2011) Diagnosing the sensitivity of local land-atmosphere coupling via the soil moisture-boundary layer interaction. J. Hydrometeor 12: 766-786.

7. Li B, Toll D, Zhan X, Cosgrove B (2012) Improving estimated soil moisture fields through assimilation of AMSR-E soil moisture retrievals with an ensemble Kalman filter and a mass conservation constraint. Hydrol. Earth Syst. Sci. 16: 105-119.

8. Zhang S, Shi J and Dou Y (2012) A soil moisture assimilation scheme based on the microwave Land Emissivity Model and the Community Land Model. Int. J. Remote Sens. 33: 2770-2792.

9. Rodriguez-Iturbe I (2000) Ecohydrology: A hydrologic perspective of climatesoil-vegetation dynamics. Water Resour. Res 36: 3-9.

10. Laio F, Porporato A, Ridolfi L, Rodriguez-Iturbe I (2001) Plants in water controlled ecosystem: Active role in hydrologic processes and response to water stress II. Probabilistic soil moisture dynamics. Adv. Water Resour 24: 707-723.

11. Rigby JR, Porporato A (2006) Simplified stochastic soil-moisture models: a look at infiltration. Hydro. Earth Syst. Sci 10: 861-871.

12. Reichle RH, Kumar SV, Mahanama SPP, Koster RD, Liu Q (2010) Assimilation of satellite-derived skin temperature observations into land surface models. J. Hydrometeor 11: 1103-1122.

13. de Rosnay P, Drusch M, Vasiljevic D, Balsamo G, Albergel C (2012) A simplified Extended Kalman Filter for the global operational soil moisture analysis at ECMWF. Q. J. R. Meteorol. Soc 139:1199-1213.

14. Dharssi I, Bovis K, Macpherson B, Jones C (2011) Operational assimilation of ASCAT surface soil wetness at the Met Office. Hydrol. Earth Syst. Sci. Discuss 8: 4313-4354.

15. Sahoo AK, De Lannoy GJ, Reichle RH, Houser PR (2013) Assimilation and downscaling of satellite observed soil moisture over the Little River Experimental watershed in Georgia, USA. Adv. Water Resour. 52: 19-33.

16. Pellenq J, Kalma J, Boulet G, Saulnier GM, Wooldridge S, et al. (2003) A disaggregation scheme for soil moisture based on topography and soil depth. J. Hydrol 276: 112-127.

17. Merlin O, Al Bitar A, Walker JP, Kerr Y (2009) A sequential model for disaggregating near-surface soil moisture observations using multi-resolution thermal sensors. Remote Sens. Envrion 113: 2275-2284.

18. Merlin O, Escorihuela MJ, Mayoral MA, Hagolle O, Bitar AA, et al. (2013) Self-calibrated evaporation-based disaggregation of SMOS soil moisture: An evaluation study at $3 \mathrm{~km}$ and $100 \mathrm{~m}$ resolution in Catalunya, Spain. Remote Sens. Environ. 130: 25-38.

19. Das NN, Entekhabi D, Njoku EG (2011) An algorithm for merging SMAP 
Citation: Hsu C, Johnson LE, Zamora RJ, Schneider T, Cifelli R (2015) Downscaling Advanced Microwave Scanning Radiometer (AMSR-E) Soil Moisture Retrievals Using a Multiple Time-Scale Exponential Rainfall Adjustment Technique. J Geophys Remote Sensing 4: 139. doi: 10.4172/2169-0049.1000139

Page 15 of 15

radiometer and radar data for hihg-resolution soil-moisture retrieval. IEEE Trans. Geosci. Remote Sens. 49: 1504-1512.

20. Piles M, Camps A, Vall-llossera M, Corbella I, Panciera R, et al. (2011) Downscaling SMOS-derived soil moisture using MODIS Visible/Infrared data. IEEE Trans. Geosci. Remote Sens. 49: 3156-3166.

21. Choi M, Jacobs JM, Bosch DD (2008) Remote sensing observatory validation of surface soil moisture using Advanced Microwave Scanning Radiometer E, Common Land Model, and ground based data: Case study in SMEX03 Little River Region, Georgia, U.S. Water Resour. Res. 44: W08421.

22. Choi M, Hur Y (2012) A microwave-optical/infrared disaggregation for improving spatial representation of soil moisture using AMSR-E and MODIS products. Remote Sens. Environ. 124: 259-269.

23. Calvet JC, Wigneron JP, Walker J, Karbou F, Chanzy A, et al. (2011) Sensitivity of passive microwave observations to soil moisture and vegetation water content: L-band to W-band. IEEE Trans. Geosci. Remote. Sens., 49:1190 1199.

24. Teuling AJ, Uijlenhoet R, Hupet F, Troch PA (2006) Impact of plant water uptake strategy on soil moisture and evapotranspiration dynamics during dry down. Geophys. Res. Letters 33: 1-4.

25. Baldocchi DD, Xu L (2007) What limits evaporation from Mediterranean oak woodlands: the supply of moisture in the soil, physiological control by plants or the demand by the atmosphere? Adv. Water Resour 30: 2113-2122.

26. Villegas JC, Breshears DD, Zou CB, Law DJ (2009) Ecohydrological controls of soil evaporation in deciduous drylands: how the hierarchical effects of litter patch and vegetation mosaic cover interact with phenology and season. J. Arid Environ 74: 595-602.

27. Atchley AL, Maxwell RM (2011) Influences of subsurface heterogeneity and vegetation cover on soil moisture, surface temperature, and evapotranspiration at hillslope scales. Hydrogeol. J 19, 289-305.

28. Teuling AJ, Uijlenhoet R, Hurkmans R, Merlin O, Panciera R, et al. (2007): Dryend surface soil moisture variability during NAFE'06. Geophys. Res. Letters, 34: 1-5.

29. Paloscia S, Santi E (2003) A semi-empirical algorithm for estimating soil moisture from dual-frequency microwave AMSR data. Preprints, Proc. IGARSS 2003, Toulouse, France, IEEE International, 1: 677-679.

30. Draper CS, Walker JP, Steinle PJ, De Jeu RA, Holmes TR (2009) An evaluation of AMSR-E derived soil moisture over Australia. Remote Sens. Environ 113: 703-710.

31. Stromberg JC, Tiller R, Richter BD (1996) Effects of groundwater decline on riparian vegetation of semiarid regions: the San Pedro River, Arizona, USA. Ecol. Applications, 6: 113-131.

32. Douglas MW, Maddox RA, Howard K, Reyes S (1993) The Mexican monsoon. J. Climate 6: 1665-1667.

33. Newman AJ, Johnson RH (2012) Simulation of a North American monsoon gulf surge event and comparison to observations. Mon. Wea. Rev 140: 2534-2554.

34. Maddox RA, McCollum DM, Howard KW (1995) Large-scale patterns associated with severe summertime thunderstorms over central Arizona. Wea. Forecasting 10: 763-778

35. Stensrud DJ, Gall RL, Nordquist MK (1997) Surges over the Gulf of California during the Mexican monsoon. Mon. Wea. Review 125: 417-437.

36. Njoku E, Jackson T, Lakshmi V, Chan T, Nghiem S (2003) Soil moisture retrieval from AMSR-E. IEEE Trans. Geosci. Remote Sensing 41: 215-229.

37. Owe M, de Jeu R, Walker J (2001) A methodology for surface moisture and vegetation optical depth retrieval using the microwave polarization difference index. IEEE Trans. Geosci. Remote Sensing 39: 1643-1654.

38. Njoku E, Ashcroft P, Chan T, Li L (2005) Global survey of statistics of radio frequency interference in AMSR-E land observations. IEEE Trans. Geosci. Remote Sensing 43: 938-947.

39. Wagner W, Naeimi V, Scipal K, De Jeu R, Fernandez JM (2007) Soil moisture from operational meteorological satellites. Hydrol. J 15: 121-131.

40. Keefer TO, Moran MS, Paige GB (2008) Long-term meteorological and soil hydrology database, Walnut Gulch Experimental Watershed, Arizona, United States. Water Resour. Res 44.
41. Zamora RJ, Ralph MF, ClarkE, Schneider T (2011) The NOAA hydrometeorology testbed soil moisture observing networks: design, instrumentation, and preliminary results. J. Atmosph. Oceanic Tech. 28: 1129-1140.

42. Jackson TJ, Mckee LG (2009) SMEX04 bulk density and rock fraction data: Arizona. Boulder, Colorado, USA: National Snow and Ice Data Center: Digita media.

43. Chow VT, Maidment DR, Mays LW (1988) Applied Hydrology. McGraw-Hill 572

44. Yamamoto H, Miura T, Tsuchida S (2012) Advanced Spaceborne Therma Emission and Reflection Radiometer (ASTER) Enhanced Vegetation Index (EVI) products from Global Earth Observation (GEO) grid: an assessment using Moderate Resolution Imaging Spectroradiometer (MODIS) for synergistic applications. Remote Sens. 4: 2277-2293.

45. Rich PM, Dubayah R, Hetrick WA, Saving SC (1994) Using viewshed models to calculate Intercepted solar radiation: applications in ecology. Amer. Soc Photogr. Remote Sensing Tech. Papers. 524-529.

46. Fu P, Rich PM (2000) The solar analyst 1.0 manual. Helios Environmental Modeling Institute (HEMI).

47. Rodriguez-Itube I, Porporato A, Ridolfi L, Isham V, Cox D (1999) Probabilistic modeling of water balance at a point: the role of climate, soil and vegetation. Proc. Royal Soc. Lond. London, UK, The Royal Soc. A 455: 3789-3805.

48. Porporato A, Daly E, Rodriguez II (2004) Soil water balance and ecosystem response to climate change. Am. Natural. 164: 625-632.

49. Niyogi DS, Raman S (1997) Comparison of four different stomatal resistance schemes using FIFE observations. J. Appl. Meteor. 36: 1-13.

50. Jarvis PB (1976) The interpretation of the variations in leaf water potential and stomatal conductance found in canopies in the field. Phil. Trans. Roy. Soc Lond. B. 273: 593-610

51. Chen F, Dudhia J (2001) Coupling an advanced land surface hydrology mode with the Penn State/NCAR MM5 modeling system. Part 1: Model description and implementation. Mon. Wea. Review. 129: 569-586.

52. Koren V, Smith M, Cui Z, Cosgrove B, Werner K, Zamora R (2010) Modification of Sacramento soil moisture accounting heat transfer component (SAC-HT) for enhanced evapotranspiration. Silver Spring, Maryland, USA: NOAA, NWS.

53. Brooks RH, Corey AT (1966) Properties of porous media affecting fluid flow. J. Irrig. Drainage ASCE, 92(IR2), 61-68.

54. Wilson DJ, Western AW, Grayson RB, Berg AA, Lear MS, et al. (2003) Spatia distribution of soil moisture over 6 and $30 \mathrm{~cm}$ depth, Mahurangi river catchment, New Zealand. J. Hydrol. 276: 254-274.

55. Moriasi DN, Arnold JG, Van Liew MW, Bingner RL, Harmel RD, et al. (2007) Model evaluation guidelines for systematic quantification of accuracy in watershed simulations. Trans. ASABE 50: 885-900.

56. Pan W, Boyles RP, White JG, Heitman JL (2012) Characterizing soil physica properties for soil moisture monitiring with the North Carolina Environment and Climate Observing Network. J. Atmos. Oceanic Technol. 29: 933-944

57. Noilhan J, Planton S (1989) A simple parameterization of land surface processes for meteorological models. Mon. Wea. Review 117: 536-549.

58. Lee TJ, Pielke RA (1992) Estimating the soil surface specific humidity. J. Appl. Meteor. 31: 480-484.

59. Merlin O, Bitar AA, Walker JP, Kerr Y (2010) An improved algorithm for disaggregating microwave-derived soil moisture based on red, near infrared and thermal-infrared data. Remote Sens. Environ. 114: 2305-2316.

60. Chanzy A, Bruckler L (1993) Significance of soil surface moisture with respect to daily bare soil evaporation. Water Resour. Res. 29: 1113-1125.

61. Cordova JR, Rodriguez II (1985) On the probabilistic structure of storm surface runoff. Water Resour. Res. 21: 755-763.

62. Bhark EW, Small EE (2003) Association between plant canopies and the spatial patterns of infiltration in shrubland and grassland of the Chihuahuan desert, New Mexico. Ecosys. 6: 185-196.

63. Brooks JR, Barnard HR, Coulombe R, McDonnell JJ (2010) Ecohydrologic separation of water between trees and streams in a Mediterranean climate. Nat. Geosci. 3: 100-104. 